\title{
O EROTISMO DE HELENA NA ILÍADA: DIONISO, A PERSPECTIVA HOMÉRICA E O GOSTO DOS COMENTADORES ${ }^{1}$
}

\author{
Antonio Orlando O. Dourado-Lopes* \\ Recebido em: 06/12/2019 \\ Aprovado em: 23/12/2019
}

\begin{abstract}
RESUMO: Quando aparece na Ilíada, Helena já não está mais envolvida eroticamente com Páris, aceitando deitar-se com ele apenas porque Afrodite a obriga. Se, por um lado, o comportamento de Helena parece colocar em questão o erotismo de sua relação com Páris, por outro o poeta afirmará em Ilíada 24, 30 que foi a 'lascívia feminina' (makblosýnē) lançada por Afrodite que causou a união com Páris, consequentemente levando a tantas mortes. Como o termo 'makhlosýne' não aparece nenhuma outra vez nos poemas homéricos, alguns comentadores antigos colocaram em dúvida a autenticidade da passagem, que introduziria segundo eles uma compreensão da relação erótica estranha à Ilíada como um todo. Todavia, o esclarecimento do termo em um escólio da Ilíada a partir da referência ao fragmento hesiódico $132 \mathrm{M}-\mathrm{W}$ (= fr. 81 Most) traz novos elementos para sua interpretação.
\end{abstract}

PALAVRAS-CHAVE: Makblosýnē; erotismo; Ilíada; Hesíodo; Afrodite.

\section{HELEN'S EROTISM IN THE ILIAD: DIONYSOS, THE HOMERIC PERSPECTIVE AND THE COMMENTATORS'TASTE}

\begin{abstract}
When she shows up in the Iliad, Helen is not any more erotically involved with Paris, accepting to lay down with him just because Aphrodite had obliged her to do so. If, on the one hand, Helen's behavior seems to call into question the erotic dimension of her relation with Paris, on the other the poet will state in Iliad 24, 30 that it was the 'feminine randiness' (makblosyne) thrown upon her by Aphrodite that created her union with Paris, causing so many deaths as
\end{abstract}

\footnotetext{
${ }^{1}$ Agradeço a revisão cuidadosa e precisa de Teodoro Rennó Assunção e de
Tatiana Ribeiro, que em muito contribuíram para o aperfeiçoamento deste

${ }^{1}$ Agradeço a revisão cuidadosa e precisa de Teodoro Rennó Assunção e de
Tatiana Ribeiro, que em muito contribuíram para o aperfeiçoamento deste artigo, bem como a revisão final de Luisa Buarque e de Alice Haddad.
} 
a consequence. Since the word makblosýne isn't used nowhere else in the Homeric poems, some ancient commentators considered the possibility of athetizing the passage, because it would introduce in the poem an understanding of the erotic relation incompatible to the Iliad as a whole. Nevertheless, the explanation of this term in a scholion to the passage based on a reference to the Hesiodic fragment $132 \mathrm{M}-\mathrm{W}$ (= fr. 81 Most) adds new elements to its interpretation.

KEYWORDS: Makblosynē; erotism; Iliad; Hesiod; Aphrodite.

$\mathrm{P}$

ara introduzir a temática deste estudo, lembremo-nos da seguinte observação de Dover, reconhecido pioneiro na pesquisa dos hábitos sexuais gregos:

Pode nos chegar como uma surpresa a mais observar a inibição sexual que operou com força crescente através do período clássico. O começo e final desse processo histórico são resumidos pelo contraste entre Ilíada 24, 129-31, onde a deusa Tétis diz a seu filho Aquiles, 'Por quanto tempo você consumirá seu coração, sem pensamento para comida ou cama? É bom deitar-se amorosamente com uma mulher', e a rejeição alexandrina dessa passagem como uma interpolação, baseando-se no fato de que 'É inadequado para uma mãe dizer isso a seu filho' ou 'é inapropriado para um herói e uma deusa'. Uma linguagem totalmente desinibida era a norma na comédia aristofânica; pelo final do século quarto ela era raramente ouvida no palco cômico. Aristóteles, observando a esse respeito (Eth. Nicom. 1122a22-4), chama a linguagem sexual direta aiskhrología, etimologicamente, 'falar o que é vergonhoso' (ou '... feio'). A literatura séria do período tendia a ser circunspecta na expressão, até mesmo recatada, embora não reticente no conteúdo. ${ }^{2}$

As mudanças no modo de exprimir o erotismo entre o início e o final do período clássico (aprox. 507-322 a.C.), apontadas pelo grande helenista, ajudam-nos a contextualizar historicamente a problemática das mudanças de costumes sofridas pelos gregos ao longo

\footnotetext{
${ }^{2}$ Dover (1974, p. 206-207): "It may come as a further surprise to us to observe the sexual inhibition which operated with increasing strength throughout the classical period. The beginning and end of this historical process are summed up by the contrast between Iliad 24, 129-31, where the goddess Thetis says to her son Achilles, 'How long will you eat your heart out, with no thought for food or bed? It is good to lie with a woman in love', and the Alexandrian rejection of the passage as an interpolation on the grounds that 'It is unseemly for a mother to say this to her son' or 'it is inappropriate to a hero and a goddess'. Totally uninhibited language was the norm in Aristophanic comedy; by the late fourth century it was seldom heard on the comic stage. Aristotle, remarking on this effect (Eth. Nicom. 1122a22-4), calls direct sexual language aiskhrología, etymologically, 'speaking what is shameful' (or '... ugly'). The serious literature of the period tended to be circumspect, even coy, in expression, although not reticent in content." Como exemplos o autor cita Demóstenes 19, 309; Xenofonte Hieron 1.4; Ésquines I, 38, 52, 55, III 162; Demóstenes, Vidas 9, 17.
} 
desse período. Esse complexo processo não poderia deixar de exercer grande influência sobre a recepção da tradição poética anterior, em especial os poemas homéricos e os hesiódicos, como exemplificado pelos versos da Ilíada citados acima.

\section{IL. 24, 22-30 E SEUS ESCÓLIOS}

Tem sido comentada desde a antiguidade a passagem em que, pouco após o início do último canto da Ilíada, a voz narrativa volta a mencionar a relação entre Páris e Helena, depois de longo silêncio sobre o tema. Aquiles aviltava o cadáver de Heitor sob os olhares dos deuses e dos aqueus:

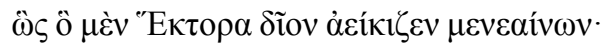

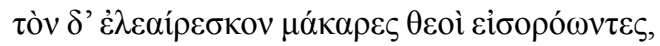

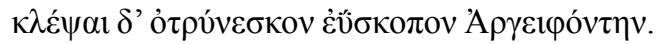

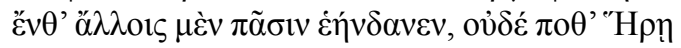

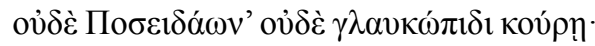

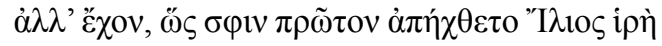

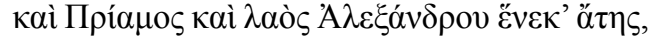

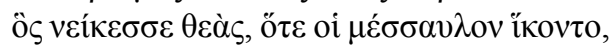

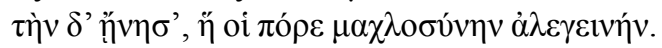

Assim ele aviltava o divino Heitor com ódio; compadeciam-se observando-o os bem-aventurados deuses, e punham-se a expedir o longevidente Argifonte para roubá-lo. Então aos demais todos isso agradou, mas jamais a Hera nem a Possêidon nem à moça de olhos luzentes, que todavia mantiveram-se como quando primeiro foi odiada Ílios sagrada e também Príamo e seu povo, por causa da demência de Alexandre, que afrontou as deusas ao encontrarem-no no pátio, pois enalteceu a que lhe franqueou a lascívia dolorosa. $(\text { Il. } 24,22-30)^{3}$

Como tem sido observado desde a antiguidade, essa passagem surpreende tanto por anunciar, apenas ao final da narrativa, mais uma causa para a fuga de Helena de Esparta e, consequentemente, da própria guerra de Troia, quanto por introduzir, pela primeira e única vez nos poemas homéricos, o termo makblosíné, 'lascívia', atribuindo-o a Helena. O contexto sugere que a makblosýné comporia com a 'demência' (átê) do príncipe troiano, mencionada dois versos antes $(I l .24,28)$ e dezessete outras vezes anteriormente no poema, o quadro

\footnotetext{
${ }^{3}$ Os textos gregos citados neste estudo da Ilíada e da Odisseia são editados por Helmut van Thiel (Van Thiel, 1996 e 1991, respectivamente). Esta e as demais traduções dos textos em línguas antigas e modernas são de minha autoria.
} 
psicológico da decisão de Páris e de Helena ao fugir para Troia. ${ }^{4}$ A se julgar por esses dados, o poema teria deixado para seus momentos finais a indicação de uma resposta à pergunta sobre a intencionalidade da participação de Helena na sua partida de Esparta, aproveitandose da ausência do marido para abandoná-lo e à filha do casal.

A estranheza causada por essa revelação inesperada e tardia aparece nos comentários de escoliastas antigos conservados pela tradição dos manuscritos medievais, que Erbse editou da seguinte forma:

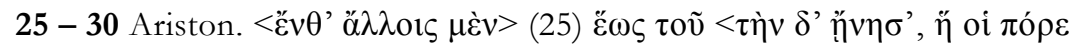

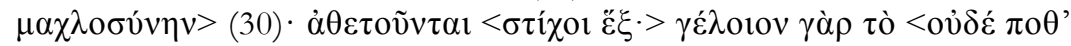

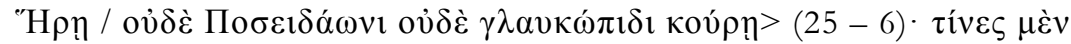

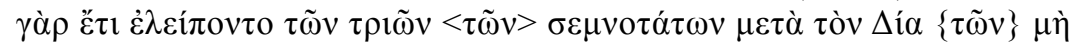

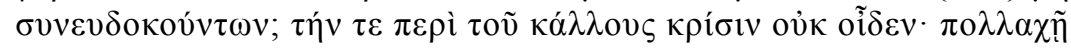

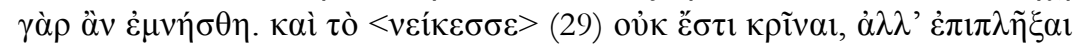

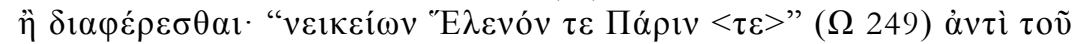

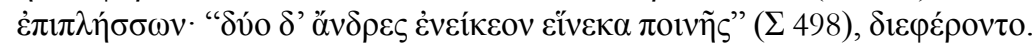

25 - 30 Ariston. <então, de um lado, a outros> (25) até o <enalteceu [éeinèsse], por outro lado, a que lhe franqueou lascívia [makblosínèn] $>$ (30): atetizam $<$ seis versos:> pois é ridículo o < jamais a Hera / nem a Possêidon nem a Atena de olhos luzentes $>(25-6)$ : com efeito, restavam ainda alguns dos três $<\operatorname{dos}>$ mais veneráveis [triôn tôn semnotátōn] depois de Zeus \{dos\} que não o aprovaram com ele [syneudokointōn]; e não sabe do julgamento acerca da beleza: pois se teria lembrado em muitas outras partes. E o <afrontou [neíkesse] $>$ (29) não é julgar [krînai], mas desferir uma punição [epipléx́ai] ou desavir-se com [diaphéresthai]: "afrontando [neikéón] tanto Heleno <quanto> Páris" $(\Omega$ 249) em vez do "desferindo uma punição" [epiplésssōn]; "e dois homens afrontavamse [eneikeoon] por causa do resgate" ( $\Sigma$ 498), desaviam-se [diephéronto].

Em que pese o estilo tipicamente sucinto dos escólios, temos aqui elementos suficientes para especular sobre os pressupostos teológicos e poéticos atuantes nessa interpretação da Ilíada, atribuída no manuscrito 'Venetus A' da Ilíada a Aristônico de Alexandria, o qual muito provavelmente a teria retomado de Aristarco de Samotrácia. ${ }^{5} \mathrm{O}$

\footnotetext{
${ }^{4}$ Traduzo ǻn por ‘demência’ para abranger tanto seu sentido psicológico de ‘delírio' quanto o físico, ou fisiológico, como consequência do ato de 'prejudicar' exprimido pelo verbo óó $\omega$ - aqui, relativamente à inteligência - e, na tradução, pelo prefixo latino 'de-'. Cf. Lewis; Short, 1879, s.v. 'de-', como um prefixo in II.d: "giving a bad sense to the verb: decipio, delinquo, deludo, derideo, detestor"; s.v. 'demens' e 'dementia'; Glare, 1968, s.v. 'de-'). Para uma ampla reflexão sobre a öın na Ilíada, ver Malta, 2006.

5 'Codex Venetus Marcianus 454' ou simplesmente 'Venetus A'. Para a atribuição da autoria dos textos originais reproduzidos como escólios a esse manuscrito, em particular sobre a dependência de Aristônico de Alexandria em relação a Aristarco de Samotrácia, ver sobretudo Dickey (2007, p. 3-28; em especial p. 18-19), que explica a relação entre o chamado 'Comentário dos Quatro Homens' ('Vier Männer Kommentar' ou VMK), que designa o acréscimo, no século IV d.C., de trechos das obras

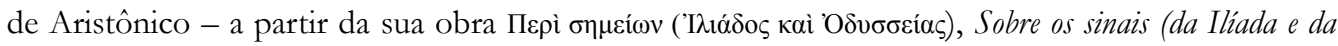


escólio protesta contra a dissociação entre a máxima venerabilidade dos três deuses (triōn tôn semnotátōn) nomeados em Il. 24, 25-26 e o júbilo de Zeus àquela altura, de que deveriam partilhar (syneudokeinn). Característico da atividade editorial dos eruditos da Alexandria helenística (e dos sucessores que os emularam), esse julgamento severo condena cabalmente o fracasso do autor do referido trecho em conduzir, na ordem ou no tempo adequados, a narrativa rumo a um acordo ou júbilo comum (syneudokia) dos deuses mais veneráveis com Zeus.

O verbo syneudokéó, 'aprovar' ou 'rejubilar-se conjuntamente', aqui empregado, compõe-se da preposição syn-, 'com', 'em conjunto com', 'simultaneamente', como prefixo, e do verbo eudokéé, 'alegrar-se', 'contentar-se com', e pode ser considerado, nesse contexto, uma versão formada no período clássico e integrada na prosa helenística dos verbos homéricos ainéo, 'enaltecer', empregado em Il. 24, 30 para exprimir a predileção de Páris por Afrodite, e do derivado, de sentido próximo, epainéo, 'elogiar', empregado duas vezes na Ilíada (2, 335 e $18,312)$ e frequente no vocabulário filosófico e retórico do período clássico. Por outro lado, na medida em que exprime o prazer gerado pela admiração por alguém, o verbo syneudokéó também pode ser aproximado dos homéricos ágamai, 'maravilhar-se (com)', 'admirar', ou, em sentido negativo, 'invejar', e gánymai, 'alegrar-se (com)', 'rejubilar-se'. ${ }^{6}$ Em suma, compondo o retrato aristocrático da sociedade homérica, a divina e a humana, syneudokéó corresponderia em geral à transposição para o vocabulário clássico - e posteriormente assimilado pela filologia helenística - dos verbos homéricos ainéó, epainéó, ágamai e gánymai, que originalmente exprimiam, com ênfases específicas, a aprovação, a admiração e o júbilo com as grandiosas ações dos deuses e dos combatentes das grandes guerras do passado.

Além da transposição do vocabulário homérico para a terminologia afim com os procedimentos argumentativos e analíticos da exegese alexandrina, a expressão 'ainda restavam' (éti eleíponto) sugere, por parte do escólio, a expectativa de uma progressiva adesão dos deuses ao júbilo de Zeus ao longo da narrativa, após a morte de Heitor no canto 22: seria admissível alguma discordância entre os deuses, mas não no último canto nem, muito menos, atribuindo aos outros deuses critérios de exigência ainda mais rigorosos que os do próprio Zeus. Como essa concepção teleológica da narrativa homérica pressupõe que o plano (boulê ) do deus supremo promovesse uma coesão progressiva e contínua entre os principais deuses, sua falta ao final do poema caracterizaria um desgoverno - da parte de Zeus e, nessa perspectiva, também do poeta - inaceitável.

Atentando contra a superioridade do júbilo de Zeus, a incongruência entre os deuses ao final da narrativa torna Il. 24, 25-26 algo 'ridículo' (geloîon) para o escoliasta. Essa visão exageradamente programática dos deuses retoma a tradicional atribuição aos poemas homéricos de uma função de fundação da religião grega, transmitida por autores diversos

Odisseia) -, de Dídimo, de Herodiano e de Nicanor às margens do manuscrito 'Venetus A' da Ilíada. Todos os quatro autores compuseram obras baseadas na filologia alexandrina dos séculos III-II a.C., que citam abundantemente, em especial os comentários de Aristarco: "Aristonicus' treatise on signs, composed in the Augustan period, was a compilation of excerpts from one of Aristarchus' commentaries and from other works, focusing on critical signs" (op. cit., 19). Ver também Pfeiffer (1968, p. 211-213).

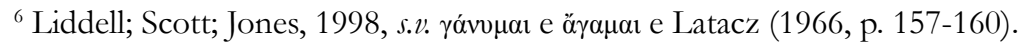


desde a época arcaica. ${ }^{7}$ Desse ponto de vista, a Iliada e a Odisseia seriam poemas veneráveis, de modo a acolherem, condignamente, um discurso venerável sobre os deuses. ${ }^{8}$ Levando às últimas consequências o rigor de seus expedientes críticos, Aristarco denuncia a inépcia de um impostor que teria descaracterizado a poesia homérica a ponto de gerar o riso, pervertendo sua contribuição ancestral.

No entanto, como argumentado em um célebre estudo de Friedländer (1934), haveria na religião e na poesia grega arcaica uma complementaridade intrínseca entre o tom cômico e o elevado. Na Ilíada ela seria principalmente exemplificada pelos episódios do 'engano de Zeus' (Diòs apátē: Il. 14, 153-362) e do 'combate dos deuses' (theomakbia: Il. 20, 1-66 e 21, 328-514), na Odisseia pelo caso de amor adúltero entre Ares e Afrodite, cantado por Demódoco aos feácios (Od. 8, 256-366):

Que Zeus seja subjugado às grandes potências da vida natural, a Eros, o qual 'todos os seres humanos e todos os deuses doma', ou ao Sono que vence a todos, não é o que o rebaixa em sua dignidade. Ao contrário. Em um átimo seu poder é recuperado. Exatamente pelo fato de que tinha adormecido por um instante ele é tanto mais irresistível depois de acordar. Contudo seu sorriso é o desfrute dessa renovada majestade. [...] O mito grego, que ganha pela primeira vez em Homero sua grande forma, essa visão de mundo, mais do que isso: essa criação do mundo, tem como sonoridade necessária, sem a qual o todo não soaria como um conjunto harmonioso, ainda menos em meio à seriedade majestosa, o jogo divino, a participação e a interferência divinas no jogo, o sorriso e as gargalhadas divinos. A Ilíada narra as coisas mais sérias e aniquiladoras, aquilo que era a mais alta preocupação e o modelo para o homem daquele tempo. Mas esse mundo só se torna inteiro quando o riso dos deuses ressoa uma vez mais por um instante. ${ }^{?}$

\footnotetext{
${ }^{7}$ Dourado-Lopes (2010), com as indicações bibliográficas.

${ }^{8}$ Zaidman (2001, p. 92-93) remete a Benveniste (1969, v. 2, p. 202-207) para chamar a atenção para

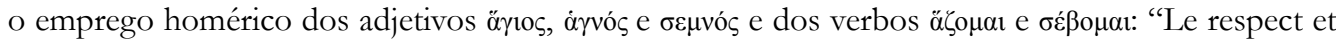
l'obéissance aux dieux que suggèrent ces différents mots sont manifestés par les dons que les hommes leur destinent, à côté des prières."

${ }^{9}$ Friedländer (1934, p. 220): “Daß Zeus den großen Mächten des natürlichen Lebens unterliegt, dem Eros, der 'alle Menschen und alle Götter bändigt, oder dem Allbezwinger Schlaff, ist nicht was ihn in seiner Würde herabsetzt. Im Gegenteil. In einem Nu ist seine Macht wiederhergestellt. Gerade dadurch daß sie einen Augenblick eingeschläfert war, ist sie nach dem Erwachen um so unwiderstehlicher. Sein Lächeln aber ist der Genuß dieser erneuten Majestät. [...] Der griechische Mythos, der im Homer seine erste große Gestalt gewinnt, diese Weltansischt, mehr als das: diese Weltschöpfung hat als notwendigen Klang, ohne den das Ganze nicht Zusammenklang wäre, gerade inmitten des majestätischen Ernstes das göttliche Spiel, das göttliche Mitspielen und Dreinspielen, das göttliche Lächeln und Gelächter. Die Ilias erzählt von den ernstesten und vernichtendsten Dingen, von dem was dem Menschen jener Zeit höchstes Anliegen und Muster menschlichen Daseins war. Aber diese Welt wird erst ganz, wenn
} 
Para o que nos interessa mais imediatamente aqui, observemos que tanto o 'engano de Zeus' quanto a narrativa do adultério de Ares e Afrodite consistem em versões burlescas da complementaridade antitética entre guerra e erotismo, enquanto a 'batalha dos deuses' restringe-se à temática da guerra (podendo ser considerada, nesse sentido, uma versão burlesca da éris anunciada como tema principal no prólogo do poema). ${ }^{10} \mathrm{O}$ tom burlesco dessas três histórias determina que os desdobramentos violentos - que uma narrativa heroica levaria até o final - sejam habilmente interrompidos: no 'engano de Zeus', embora colérico ao acordar, ele apenas ameaça Hera e sequer se refere à participação do Sono - contrariamente ao que teria feito anteriormente em uma situação análoga (Il. 14, 242-262); no 'combate dos deuses', aqueles que se enfrentavam dois a dois ou preparavam-se para fazê-lo em breve afastam-se após combater ou simplesmente acabam por se decidirem subitamente pela trégua (Il. 21, 435-514); no adultério de Ares e Afrodite, Possêidon negocia com o marido traído, Hefesto, a liberação dos amantes e afiança pessoalmente o pagamento da penalidade por Ares $(O d$. 8 , 344-366). ${ }^{11}$ Esses e outros exemplos sugerem que teria havido desde os poemas homéricos certa continuidade em torno a uma compreensão variada da comicidade. ${ }^{12}$ Os exemplos acima

das Lachen der Götter immer wieder für Augenblicke hineinklingt.” Em atenção ao contexto, traduzo a expressão 'Zusammenklang sein', que significa literalmente 'ser um som (Klang) conjunto (zusammen)', por 'soar como um conjunto harmonioso'.

${ }^{10}$ A éris ('luta', 'disputa') é anunciada como tema principal da Ilíada no prólogo do poema, através

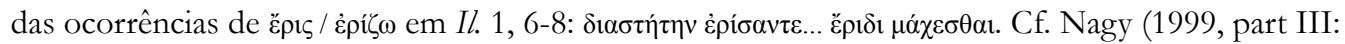
"Praise, Blame, and the Hero", cap. 11-15; em particular cap. 11, 』12, p. 218-219, onde o autor chama a atenção para o par éris e nểkos).

${ }^{11}$ Burkert (1960) retomou e desenvolveu a tese de Friedländer sobre o cômico homérico, concentrandose particularmente no episódio do adultério de Ares e Afrodite, sobre o qual afirma (op. cit., p. 140): “Como resultado deixa-se concluir que a canção de Demódoco, de um lado, está firmemente enraizada na construção de conjunto da nossa Odisseia, de outro lado, ao mesmo tempo sintetiza e transforma as mais importantes cenas divinas da Ilíada." ("Als Ergebnis läßt sich zusammenfassen, daß das Demodokos-Lied einerseits im Gesamtbau unserer Odyssee fest verwurzelt ist, andererseits die wichtigsten Götterszenen der Ilias gleichzeitig zusammenfaßt und verwandelt.”). Sobre o mesmo episódio, ver ainda Assunção (2014), que também valoriza sua inserção no conjunto da Odisseia, em particular a oposição entre o modelo monogâmico de casamento e as aventuras eróticas de Odisseu com as ninfas Calipso e Circe (op. cit., p. 77): “[...] estas brechas discretas em relação à moral monogâmica (maximamente explicitadas na estória do adultério de Ares e Afrodite e do segundo riso de Apolo e Hermes) não constituem e nem conseguem quebrar de todo a tônica da narrativa principal, onde o duplo adultério dos pretendentes, por cortejarem a mulher de um homem ainda vivo e se deitarem (fora do quadro do casamento) com algumas escravas infiéis de um outro senhor, é - como o das escravas infiéis - punido, sem exceção, com a morte por este marido e senhor (com seus três auxiliares) que pode, enfim, reassumir o seu lugar e se reencontrar em amor com a mulher longamente fiel." ${ }^{12}$ Halliwell (1991) estudou as várias dimensões do cômico na literatura grega desde o período arcaico, analisando seu variado vocabulário (p. 280-281, com a nota 5), comentando trechos dos poemas homéricos (p. 281-282), distinguindo o riso brincalhão do consequente (p. 283 e 285-286) e observando conclusivamente (p. 293): "The two poles around which views of laughter tend to 
mostram, portanto, que os poemas homéricos recorreram programaticamente à comicidade para abordar os vínculos entre erotismo e belicosidade como uma oposição complementar, na medida em que são representados como manifestações impulsivas do corpo humano divino ou mortal, como decisões do thymós.

Nos escólios reunidos por Erbse aos versos seguintes, a menção a uma 'lascívia' é aduzida como um motivo a mais para a atetização do verso 30 :

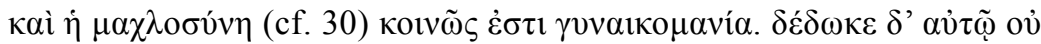

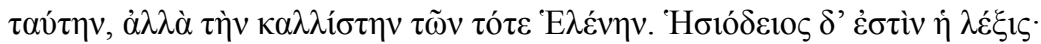

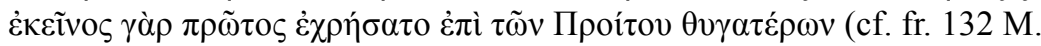
$-\mathrm{W}$.). $\mathbf{A}$

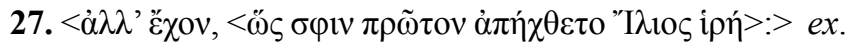

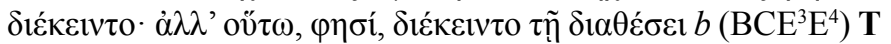
$\dot{\omega} \varsigma \dot{\alpha} \pi$ ' $\alpha \dot{v} \tau \tilde{\eta} \varsigma \tau \tilde{\eta} \varsigma \dot{\alpha} \rho \chi \tilde{\eta} \varsigma . ~ \mathbf{b}\left(\mathrm{BCE}^{3} \mathrm{E}^{4}\right)$

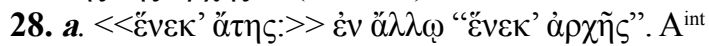
Did. (?)

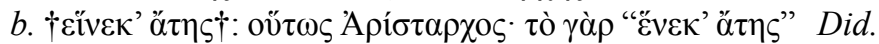

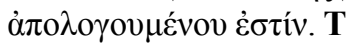

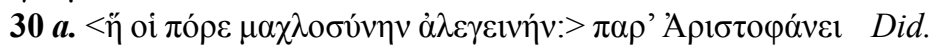

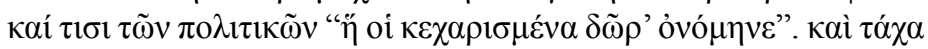

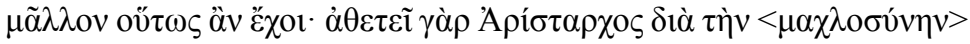

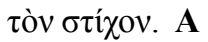

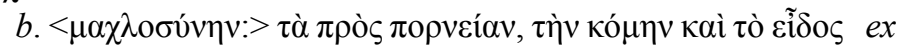
(cf. Г 55). b $\left(\mathrm{BCE}^{3} \mathrm{E}^{4}\right) \mathbf{T}$

E a lascívia (cf. 30) é comumente a loucura pelas mulheres [gynaikomanía]. Deu-lhe [scil. a Páris] não essa, mas a mais bela das [mulheres] de então, Helena. O termo é hesiódico: pois aquele pela primeira vez o utilizou nas filhas de Proitos (cf. fr. 132 M. - W.). A

27. $<$ mas mantinham-se, $<$ como quando para eles primeiramente era odiada a sagrada Ílios $>$ : $>$ dispunham-se [psiquicamente]: mas assim, diz, colocavam-se na disposição [psíquica] $\mathbf{b}\left(\mathrm{BCE}^{3} \mathrm{E}^{4}\right) \mathbf{T}$

como se a partir do próprio começo. $\mathbf{b}\left(\mathrm{BCE}^{3} \mathrm{E}^{4}\right)$

$<<$ por causa da demência:>> em outro "por causa do começo" A ${ }^{\text {int }}$ Did. tpor causa da demênciał: assim Aristarco: pois o "por causa da demência" Did. é do [scil. trecho] defendido. T.

30 a $<$ a qual the franqueou a lascívia dolorosa: $>$ junto a Aristófanes Did.

be concentrated represent, therefore, a kind of perpetual tension between the spirit of celebratory, playful release and the forces of derisive antagonism, a tension which was handled by the shaping and constraining functions of both ethical attitudes and specific social practices." Analisando em especial o Ájax de Sófocles, Barbosa (2008, p. 91) mostra como o riso faz parte dos recursos expressivos e dramáticos da tragédia: "O riso, na sociedade grega do período clássico, oscila entre a celebração da vida e a ostentação do culto ao antagonismo. É expressão de liberação e alegria e ao mesmo tempo manifestação de ódio e execração.” 
e a alguns dos políticos "a qual lhe nomeou presentes agradáveis". E talvez fosse mais assim: pois Aristarco atetiza o verso por causa da $<$ lascívia $>$. A

b < lascívia: $>$ as coisas relativas à prostituição, à cabeleira e à beleza corporal (cf. $\Gamma$ 55). b (BCE $\left.{ }^{3} \mathrm{E}^{4}\right) \mathbf{T}^{13}$

Interpretando a 'lascívia' em Il. 24, 30 como o que 'comumente' (koinôs) equivaleria à gynaikomanía, a 'loucura pelas mulheres', ou seja, ao desejo irresistível, desenfreado, pelas mulheres, o escoliasta a considera uma doença que teria afligido Páris, atribuindo ao sofrimento dele a qualificação por 'dolorosa' (alegeiné) no verso homérico. Por outro lado, gynaikomanía também parece remeter diretamente à ocorrência do adjetivo gynaimanés em relação ao mesmo Páris, empregado pela primeira vez no início da admoestação veemente de Heitor:

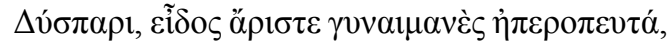

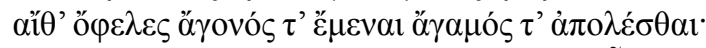

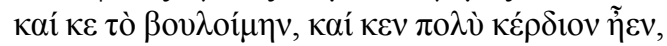

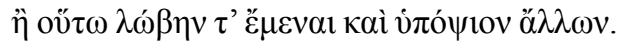

'Dis-páris', o melhor na forma, louco por mulheres, embusteiro! Quem dera não teres filhos e sem casar-te morreres!

Isso eu quereria, e seria muito mais vantajoso do que seres assim uma injúria e visto com desconfiança pelos outros. (Il. 3, 39-42)

O adjetivo reaparecerá apenas mais uma vez no poema (e nunca mais na epopeia arcaica), em uma segunda admoestação de Heitor a seu irmão:

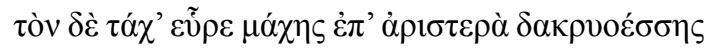

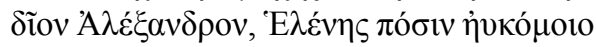

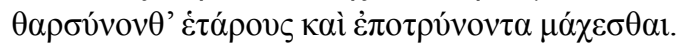

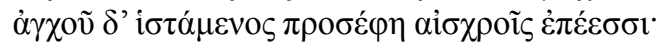

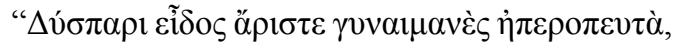

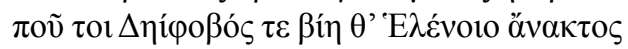

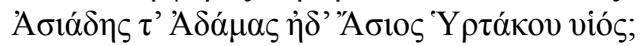

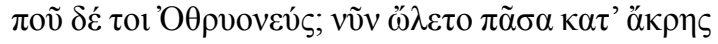

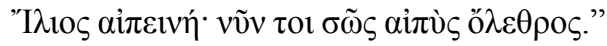

Logo encontrou à esquerda da luta lacrimosa o divo Alexandre, esposo de Helena de bela cabeleira incitando os companheiros e impelindo-os a lutar. Proximamente postando-se dirigiu-lhe palavras vergonhosas: “'Dis-páris', o melhor na forma, louco por mulheres, embusteiro!

\footnotetext{
${ }^{13}$ Erbse, 1969-1988, ad Il. 24, 28-30. Traduzo literalmente o verbo 'nomear', que aqui, no aoristo ỏvó $\eta \eta v \varepsilon$, parece mais propriamente significar algo como 'anunciou' ou 'prometeu' (cf. Liddell; Scott; Jones, 1990, s.v. e Cunliffe, 1963, s.v.).
} 
Onde estão Deífobo e a força do soberano Heleno, e Adamas, o Assiades, e Ássio o filho de Irtaces? Onde está Otrioneu? Agora pereceu do alto toda Ílios íngreme; está salvo agora o íngreme perecimento! (Il. 13, 765-773)

Essas duas ocorrências de gynaimanès, 'louco por mulheres', parecem ter sugerido a Aristarco o emprego de gynaikomanía para traduzir makhlosýné por um termo contemporâneo a ele em seu comentário. No entanto, ao propor a equivalência entre makblosýnè e gynaikomania, Aristarco parece desconsiderar - ou simplesmente desconhecer - a possibilidade de que o substantivo makblosýnē tenha sido empregado anteriormente apenas em relação às mulheres. ${ }^{14}$ Por sua vez, para sustentar uma nova interpretação do casal Páris-Helena, Suter evoca as ocorrências em que gynaimanés significaria na verdade 'aquele que enlouquece as mulheres', o que nos ajuda a compreender melhor a referência a uma 'lascívia feminina desmedida (makhlosýnēe' ao final do poema. ${ }^{15}$ Antes, porém, de acompanharmos a instigante argumentação de Suter, notemos que a separação entre termos que descrevem ou qualificam situações sociais ou eróticas exclusivamente masculinas ou exclusivamente femininas é uma característica recorrente do vocabulário homérico e da poesia arcaica relativamente às relações sociais, em geral, e às de gênero e eróticas, em particular. ${ }^{16}$

\footnotetext{
${ }^{14}$ Гvvaiконаvía: "madness for women, Stoicorum fragmenta, fr. 3.167 (ed. von Arnim)" (Liddell; Scott;

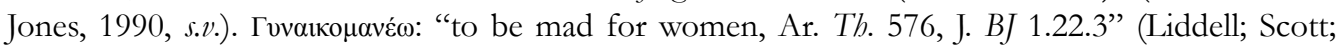

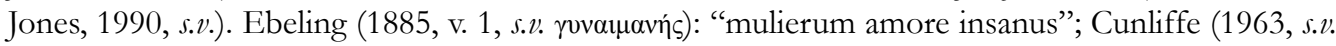

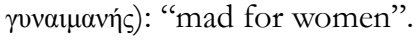

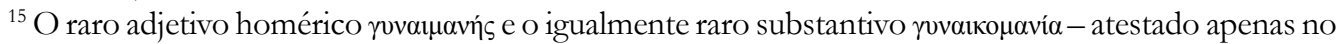
fragmento de Crisipo referido na nota anterior - são nomes compostos determinativos dependentes, segundo a terminologia de Smyth (1956), que define esse tipo como um composto em que "a substantive forming either the first or the second part stands in the sense of an oblique case (with or without a preposition) to the other part” (\$\$ 895-899, p. 252-254; em particular \$896, p. 253). O mesmo autor esclarece à frente (op. cit., p. 253, n. 1) que neles se projeta uma relação de casos de um modo puramente

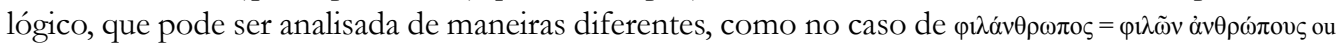
= $\varphi^{\prime} \lambda o \varsigma \alpha \grave{\alpha} v \theta \rho \omega ́ \pi \omega v$. Evocando o Lexikon des frühgriechischen Epos (1993, s.v.), e o dicionário etimológico de

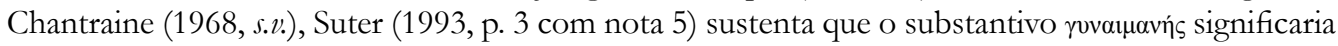
mais propriamente 'aquele que enlouquece as mulheres' ('he who drives women mad'), conforme se conclui da ocorrência mais antiga depois das duas da Iliada, no Hino homérico a Dioniso, 17 (ed. Oxford Classical Texts por Allen-Hallday-Sikes, 1936) = Hino homérico a Dioniso, 8 (Homeric Hymn 1 D, codex M, ed. West (Harvard, Loeb Classical Library, 2003). Essa mudança de passivo para ativo na compreensão do verbo, ou seja, de 'enlouquecido' para 'enlouquecedor', coloca Páris em estreita relação com Dioniso conforme veremos abaixo nas próximas referências ao estudo de Suter (1993).

${ }^{16}$ Sobre a condição feminina na perspectiva dos poemas homéricos e seus reflexos na repartição do vocabulário, ver Farron (1979, p. 15-31) e Felson; Slatkin (2004, p. 91-114). Sobre as opiniões acerca da diferença de sexos e suas características no período clássico, inclusive sexuais, ver Dover (1974, p. 95-102 e 205-16).
} 
Observe-se, por fim, que a opinião dos escoliastas ecoa ainda hoje em um importante estudioso como West (2011), para quem

parece improvável que $\mathrm{P}$ introduzisse sua única referência ao Julgamento de Páris nesse estágio tardio (cf. Il. 4, 31-36 nota), ou

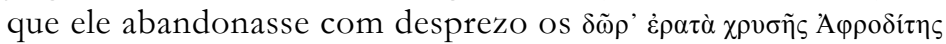
(Il. 3, 64) como makblosýne. Eu considero essas duas linhas como a interpolação de um rapsodo. Talvez o mesmo rapsodo tenha alterado 28 a partir de sua forma formular. ${ }^{17}$

Sem desconsiderar a pertinência desse ponto de vista, proponho-me a destacar em seguida as razões que nos permitem relativizar esse e outros julgamentos severos sobre $I l$. 24,30 .

\section{A makhlosínē na história das filhas de Preto}

A referência à makhlosýnē no canto 24 é inesperada, já que a trama do rapto de Helena parecia até então justificada pelo comportamento hedonista de Páris e a cativante beleza da rainha espartana. ${ }^{18}$ Assim, as consequências desse encontro já estariam suficientemente determinadas quando o início do canto 24 acrescenta uma 'lascívia' de que até então não se tinha tido notícia. Mas alguns elementos da caracterização do casal talvez revelem a coesão desse enredo. Contrariamente ao entendimento de Aristarco, que parece ter seguido a ênfase tradicional da atribuição do adultério à decisão de Páris (sem necessariamente excluir alguma participação de Helena, relegada a um vago segundo plano), a makhlosýné parece designar uma condição físico-psíquica exclusivamente feminina. Portanto, a referência a ela em $\mathrm{Il}$. 24, 30 deve ser mais propriamente interpretada como o instrumento usado por Afrodite para agir sobre Helena em suposto - e certamente perigoso - benefício de Páris, subordinando-a eroticamente a ele, ainda que provisoriamente, que então passa a ter o poder de decidir sobre o futuro do casal. Assim, todo o episódio do rapto de Helena passa a ser iluminado em flash-back por essa passagem do canto 24 como um envolvimento recíproco, tornando o casal simultaneamente agente e vítima de um erotismo irresistível e maléfico.

Para nos ajudar a esclarecer o sentido arcaico do termo makblosýnē, seja ele também originalmente homérico ou não, examinemos a segunda ocorrência mais antiga, posterior apenas à da Ilíada. Ela aparece na tentativa de reconstituição e ordenação dos fragmentos que teriam integrado o poema hesiódico conhecido como Catálogo das mulheres proposta por Merkelbach e West (Solmsen; Merkelbach; West, 1970¹; 1990³), fragmentos 131-133 M-W

\footnotetext{
${ }^{17}$ West, 2011b, ad 28-30, p. 412: “[...] it seems unlikely that P would introduce his only reference to the Judgement of Paris at this late stage (cf. $\Delta 31-6 \mathrm{n}$.), or that he would have contemptuously

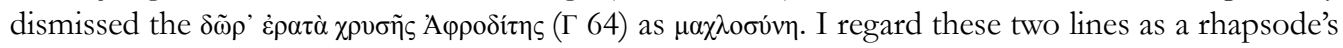
interpolation. Perhaps the same rhapsode altered 28 from its formulaic form."

${ }^{18}$ É oportuno lembrar que Helena nunca é chamada de 'rainha' na Ilíada.
} 
(= frs 81-83 Most, 2007). O primeiro fragmento é composto de duas partes, sendo a primeira um trecho da Biblioteca de Pseudo-Apolodoro (II, 2.2):

\section{Pseudo-Apolodoro, Bibliotec $A$ II, 2.2 = Hesiodi fr. $131 \mathrm{M}$-W}

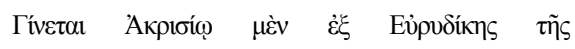

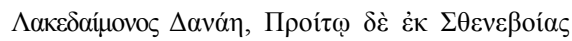

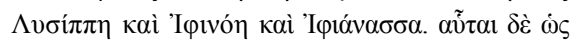

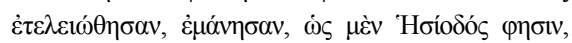

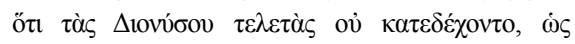

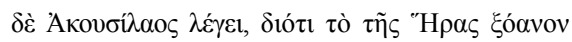
$\dot{\varepsilon} \xi \eta v \tau \dot{\lambda} \lambda 1 \sigma \alpha v$.
Nasce para Acrísio de Eurídice, a lacedemônia, Dânae, e para Preto de Estenobeia Lisipe e Ifinoe e Ifiánassa. Essas, quando se tornaram adultas, enlouqueceram, como diz Hesíodo, porque não acolheram os mistérios de Dioniso, já como diz Acusilau, porque menosprezaram a estatueta de madeira (xóanon) de Hera.

A segunda parte do fr. 131 M-W é um comentário ao verso 48 da Écloga VI de Virgílio:

Proetides implerunt falsibus mugitibus agros:

at non tam turpis pecudum tamen ulla secuta

concubitus, quamvis collo timuisset aratro

et saepe in levi quaesisset cornua fronte.

As filhas de Preto encheram os campos com falsos mugidos:

e, contudo, nenhuma empreendeu tão torpe

coito, por muito que tivesse temido o arado no pescoço

e frequentemente procurasse os chifres na leve fronte.

(Virgílio, Bucólicas VI, 48-51)

Este é o comentário de Probus (III, 2.345):

Probus in Verg. ECl. VI. 48 (III 2.345 Thilo-Hagen) = Hesiodi Fr. 131 M-W (CONTinuaÇão)

'Proetides implerunt'. Proeti filiae regis Argivorum. Hesiodus docet ex Proeto et Stheneboea Amphidamantis natas. has, quod Iunonis contempserant numen, insania exterritas, quae crederent se boves factas, patriam Argos reliquisse, postea a Melampode Amythaonis filio sanatas ita uti ***
"As filhas de Preto encheram". As filhas de Preto, rei dos argivos. Hesíodo ensina que elas eram nascidas de Preto e Estenobeia, filha de Anfidamante, as quais, porque desprezaram a imagem de Juno, desterradas por loucura, acreditaram ter sido transformadas em vacas, deixaram a pátria Argos, e posteriormente por Melampo, filho de Amitáon, foram curadas dessa forma para que $* * *$ 
O estado muito fragmentário limita o acesso ao texto dos dois fragmentos seguintes. ${ }^{19}$ O fr. 132 M-W é o trecho de um verbete do léxico bizantino Suda (século X d.C.):

$$
\text { SUdA M } 307 \text { (III. 339. } 4 \text { AdLER) = Hesiodi Fr. } 132 \mathrm{M}-\mathrm{W}
$$

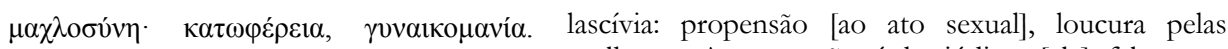

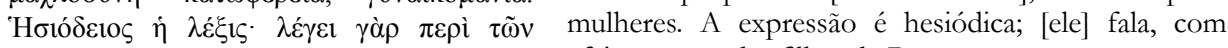
Проítov $\theta v \gamma \alpha \tau \dot{\varepsilon} \rho \omega v$. efeito, acerca das filhas de Preto:

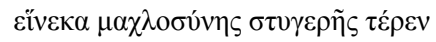
$/ / \ddot{\omega} \lambda \varepsilon \sigma \varepsilon v$ ớv $\theta \mathrm{o} \varsigma$.

por causa da lascívia odiosa consumiu //a tenra flor. ${ }^{19}$

O fr. 133 M-W aparece em um dos papiros encontrados na cidade egípcia de Oxirrinco:

P. Oxy. 2488A, ED. LobeL = HesIOdI Fr. 133 M-W

\author{
[ ] $] \delta \varepsilon .0[$ \\ [ ] $] \dot{\alpha} \pi \varepsilon i ́ p o v \alpha \gamma \alpha \tilde{\alpha} \alpha v$

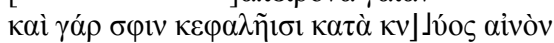 \\ //"है $\chi \varepsilon v[\varepsilon v$.

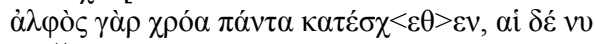

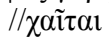

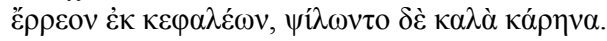

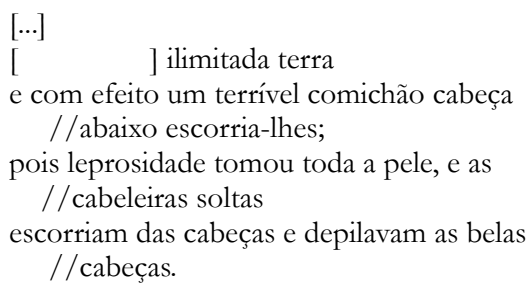

$[\ldots]$

[ ] ilimitada terra

e com efeito um terrível comichão cabeça //abaixo escorria-lhes;

pois leprosidade tomou toda a pele, e as //cabeleiras soltas

escorriam das cabeças e depilavam as belas $/ /$ cabeças.

No contexto desses fragmentos, a makhlosýnéé a doença enviada por uma divindade, presumivelmente feminina, a mulheres que a teriam afrontado ou desobedecido. ${ }^{21}$ Com a minúcia característica das descrições homéricas, esses poucos versos relatam os efeitos físicos da moléstia nas filhas de Preto. Destaca-se no verso citado pela Suda (fr. $132 \mathrm{M}-\mathrm{W}$ ) a expressão 'tenra flor', talvez parte da expressão formular 'tenra flor da juventude', que o estado do manuscrito não permite restituir. A expressão 'flor da juventude' é empregada apenas uma vez na Ilíada, quando Idomeneu pede o auxílio dos companheiros para resistir ao ataque de Eneias,

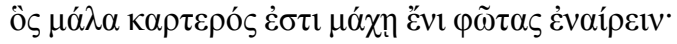

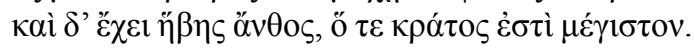

o qual é muito poderoso na luta para matar homens;

\footnotetext{
${ }^{19}$ Indico com ' //' a continuação das linhas da edição original interrompidas pela formatação adotada aqui.

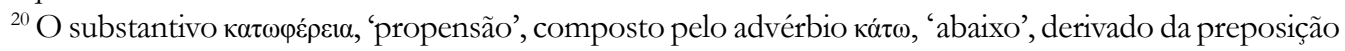

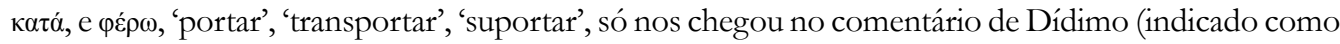
'D’ no escólio), justamente a respeito de Il. 24, 30, e como uma tradução explicativa de $\mu \alpha \chi \lambda$ oбúvๆ. Não conhecendo outros empregos do termo, não há como definirmos se a associação com a decadência moral seria um sentido comum ou se apenas uma dentre várias possibilidades.

${ }^{21}$ Davies (1981, p. 57-8).
} 
e tem a flor da juventude, cujo poder é o maior!

(Il. 13, 483-484)

O contexto militar associa a expressão hébès ánthos, 'flor da juventude', ao 'poder' (krátos) de um guerreiro sobre o adversário de combate. ${ }^{22}$ Não evoca, portanto, a sensualidade juvenil da referência hesiódica às filhas de Preto, cuja delicadeza vem realçada pelo adjetivo 'téren', 'tenro' (no neutro, qualificando ánthos, 'flor'). No contexto iliádico, 'flor da juventude' exprime o vigor que se manifesta na impetuosidade destemida da primeira adultez masculina, como em outras passagens homéricas. ${ }^{23}$ Além da associação com o vigor, as demais referências homéricas colocam a juventude (hébề) como a fase da vida desejável para quem a possui e também aquela que torna uma pessoa desejável por sua graça e beleza. Em diversas situações em que a morte se aproxima ou é anunciada, a juventude é mencionada como uma perda trágica para aquele que será privado do que a vida lhe ofereceria de melhor. ${ }^{24}$

Segundo o mitógrafo Acusilau de Argos (aprox. século VI a.C.), a moléstia que afligiu as filhas de Preto lhes teria sido enviada por Hera por terem difamado gravemente sua estatueta de culto (dióti tò tês Héras xóanon exēutélisan). Já o autor da Biblioteca cita Hesíodo para afirmar que a makhlosýnè seria a forma de 'loucura' com que as moças teriam sido punidas pela afrontosa recusa dos mistérios de Dioniso (tàs Dionýson teletàs ou katedékhonto). Seja Dioniso seja Hera a divindade responsável pela punição, a makhlosýnē consistiria em um longo período sob os efeitos de um estado de completo delírio, levando suas vítimas à autodegradação e ao isolamento. A Biblioteca informa que as filhas de Preto acabam sendo curadas pelo adivinho Melampo, quando o pai aceita dar a este dois terços de seu reino como pagamento, mas Ifínoe, a filha mais velha, acaba morrendo durante a perseguição (katà tôn diogmôn). ${ }^{25}$

\footnotetext{
${ }^{22}$ Sobre o sentido de крátos nos poemas homéricos ver Benveniste (1969, p. 71-83), que observa (p. 75-77) que "partout krátos indique la supériorité d'un homme, qu'il affirme sa force sur ceux de son camp ou sur les ennemis. Cette 'supériorité' est dite 'grande' (méga) ou 'la plus grande' (mégiston)".

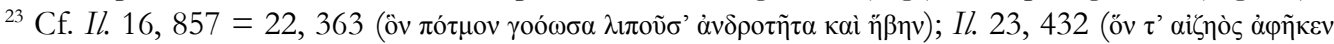

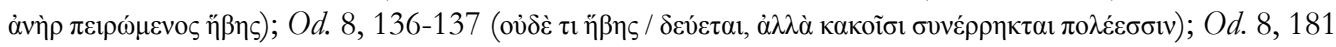

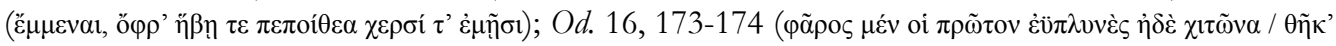

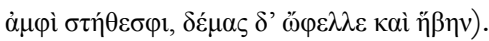

${ }^{24}$ A juventude aparece como a fase da vida que se deseja atingir e desfrutar ao máximo, e cuja perda

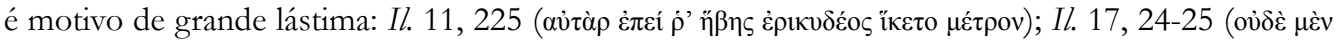

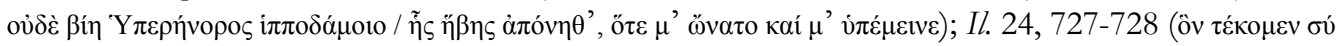

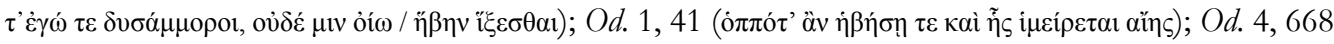

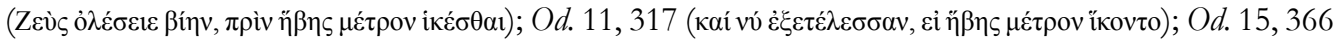

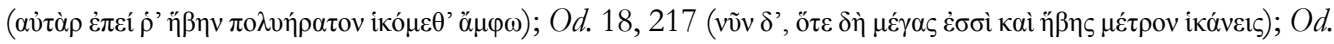

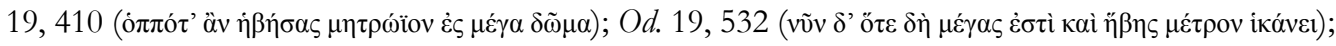

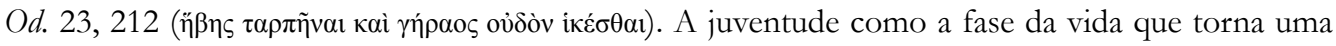

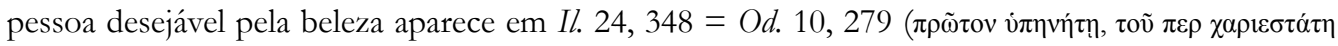

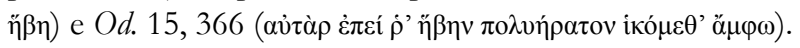

${ }^{25}$ Ps.-Apolodoro, Biblioteca 2, 2.2. Cf. notas 1 e 2 de Frazer na sua edição da Biblioteca (Ps.-Apollodorus, 1946, p. 146-147).
} 
Entretanto, a Ilíada conta apenas a sequência dessa história, também presente no relato da Biblioteca: a esposa de Preto, Estenebeia - denominada Anteia na Iliada -, apaixonase por Belerofonte mas não é correspondida; vinga-se, então, inventando um falso assédio sexual por parte do herói, indignando violentamente o rei. ${ }^{26} \mathrm{O}$ termo makblosýnè não é empregado aqui, o que se pode explicar pela ausência de menção a uma influência divina. Também é incompatível com uma intervenção divina o fato de que, diferentemente da união de Páris com Helena, a atração de Anteia por Belerofonte não se consuma eroticamente: a ação divina sobre mortais é sempre eficiente e não teria por que ser diferente neste caso. A restrição da Ilíada a essa parte da história da família de Preto, deixando de fora a afronta e a punição das filhas, pode visar a reservar a makblosýne para a ação de Afrodite sobre Helena, destacando assim o modo implacável com que a deusa exerce seu poder, associando a lascívia com a loucura.

Nos fragmentos hesiódicos, a associação da loucura com o erotismo e a restrição dessa forma de flagelo a um grupo exclusivo de mulheres podem remeter a uma modalidade de dionisismo. Essa foi a interpretação proposta por Farnell em 1921, que salientou a relação dos elementos dionisíacos do mito de Preto com a participação nele de Melampo, reiprofeta de Tirinto ou de Argos. A fonte mais antiga dessa história seria o poema hesiódico Melampódia, hoje perdido: acometidas pelo acesso de loucura enviado por Hera, as filhas de Preto erraram em delírio pelo Peloponeso, atraindo outras mulheres. ${ }^{27}$ Com efeito, a Ilíada apresenta algumas referências a Dioniso e, indiretamente, ao menadismo, revelando conhecimento do deus e de seus principais ritos e símbolos, com exceção apenas do vinho. O menadismo está sugerido quando Andrômaca, tendo ouvido a voz do sogro, partilha com as servas a desconfiança de que Heitor teria morrido (Il. 22, 449-459): "Falando isso, irrompeu do quarto tal uma mênade, / alvoroçada no coração." 28 Ainda que raras, breves e esparsas, as referências homéricas a Dioniso e ao menadismo inserem o casal Páris-Helena

\footnotetext{
${ }^{26}$ A história sobre Belerofonte, Anteia e Preto é o núcleo da narrativa sobre Belerofonte (Il. 6, 155205), que ocupa a maior parte do relato de Glauco a Diomedes sobre seus antepassados (Il. 6, 144211). Ver Graziosi; Haubold (2010, ad 155-205).

${ }^{27}$ Farnell (1921, p. 63-4): “The usual Bacchic dance consisted of women; but Melampous understood his patients, who were all restored to sanity save one. We have here a salient mythic example of the Bacchic ritual regarded as a kátharsis pathèmáthōn, and it was religious experience such as this which may have suggested to Aristotle his strange theory that tragedy, that fairest growth of the Bacchic religion, was 'a Katharsis' of certain emotions."

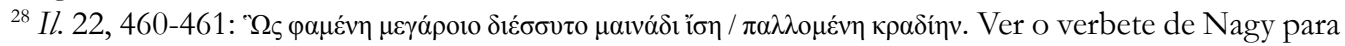
a Homeric Encyclopaedia editada por Finkelberg (in: Finkelberg, 2011, v. 1, s.v. 'Dionysos'), em particular: "Dionysos is named five times in $\operatorname{Homer}(I l .6,132$ e 135; 14, 325; Od.11, 325; 24, 74) in four different passages, two for each epic, always being loosely associated with love and/or violent death. He never appears either as part of the main narrative or as a participant of divine gatherings on Olympos." Abandonada hoje a reticência de muitos estudiosos do passado sobre a autenticidade dessas passagens, sobressai nelas a relação do deus com a loucura e com o menadismo já nos poemas homéricos. Em sua contribuição para a mesma obra, Rutherford (in: Finkelberg, 2011, v. 2, s.v. 'Maenads') cita ainda

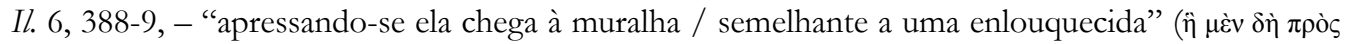


em um novo horizonte religioso, determinado pela característica relação de Dioniso com a loucura feminina.

Segundo Suter (1993), Dioniso seria o modelo de Páris, sendo o nome 'Alexandros' provavelmente mais antigo, como mostra o grau mais evoluído de desenvolvimento formular no sistema de epítetos, e o nome 'Páris' mais recente. Alguns epítetos deste nome são bápax legómena, sendo sempre abusivos, isto é, ofensivos, depreciativos, ou neles mesmos ou pelo contexto, e descrevendo comportamentos que muitas vezes podem ser associados com Dioniso:

O efeito final do epíteto de Alexandre é descrever um caráter de

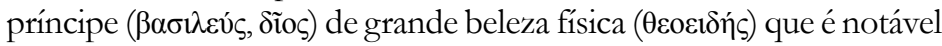

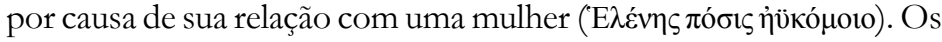
epítetos de Páris explicitam esses elementos mais especificamente, com mais vivacidade: ele é um príncipe (viòs Пpı́x́oı), um belo

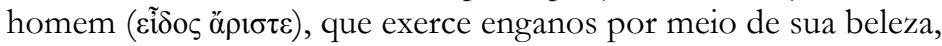

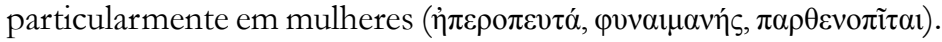
E finalmente, ele é um objeto de ofensa, em parte por causa de seu uso do arco, que não é considerado uma arma tão viril quanto a lança

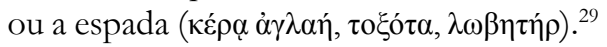

Na composição do personagem Páris Alexandre, a autora destaca seu papel como aquele que, ao ser ofendido, responde ofendendo, e relaciona-o com a apresentação de Tersites na Iliada e de Iro na Odisseia, propondo a tradição oral da poesia jâmbica como fundo comum aos três personagens. Haveria, dessa forma, influência de elementos do jambo na composição de importantes personagens homéricos caracterizados pela invectiva, que também se distinguem dos demais pelo número relativamente grande de bápax legómena empregados a seu respeito, conforme já observado anteriormente por Page. ${ }^{30}$ Suter comenta a respeito:

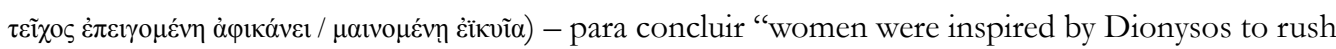
from home (sometimes from the loom)."

${ }^{29}$ Suter (1993, p. 2-4; p. 3-4 para a citação): "The net effect of the Alexandros epithet is to describe

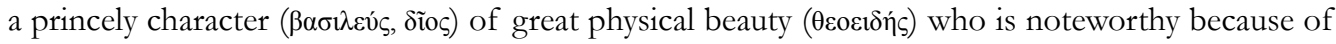

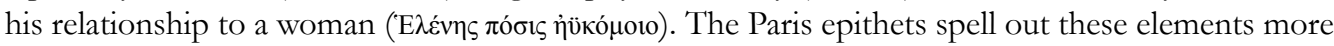

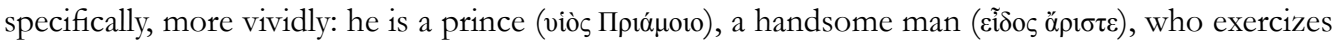

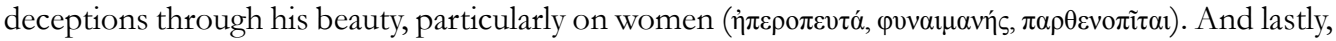
he is an object of abuse, in part because of his use of the bow, which is not considered as manly a

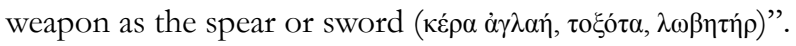

${ }^{30}$ Page (1964, p. 214; apud Suter, 1993, p. 8): “The fragment ov̉ $\varphi \imath \lambda \varepsilon ́ \omega \mu \varepsilon \dot{\gamma} \gamma \alpha v \sigma \tau \rho \alpha \tau \eta \gamma o ́ v$, is this not very much in the spirit of Homer? The description of Thersites and Iros are essentially the same; and it is to be noticed that when Homer wishes to describe a particular individual, such as Thersites, he does just what Archilochus is doing - he uses a detailed and highly specialized vocabulary, including numerous hapax eiromena." O verso citado é o primeiro do fragmento 114 West. 
Duas das três figuras homéricas que Page menciona aqui como sendo descritas à maneira 'arquiloqueia', 'jâmbica' (Iros e Tersites), são ofendedores e objetos de ofensa [abusers and objects of abuse] na narrativa dos poemas homéricos. E o 'vocabulário detalhado e altamente especializado, incluindo numerosos hapax eiromena', é precisamente o que a análise da dicção acabou de mostrar que existe para o nome Páris. Como notamos, Tersites, Iro e Páris têm todos papéis que envolvem acusar, ser acusado e a criação de conflito; os episódios nos quais eles estão envolvidos seguem padrões similares e talvez reflitam um padrão de estoque do repertório jâmbico. ${ }^{31}$

Distinguindo os conceitos de 'papéis de estoque' ('stock roles'), que seriam as características estruturais de certos modelos de personagens, e 'personagens de estoque' ('stock characters'), que seriam os próprios personagens desenvolvidos a partir desses modelos (com nome, família e região de origem, uma biografia básica etc.), a autora sustenta que a existência dos primeiros bastaria para justificar os traços comuns aos três personagens analisados por ela, Tersites, Iro e Páris. ${ }^{32}$ Ainda que seja difícil precisar o contexto social da poesia de invectiva que deu origem ao jambo da idade arcaica, na qual esses modelos teriam sido formados, supõe-se que em boa parte isso teria acontecido em rituais de festivais dionisíacos. Favorecendo a mimetização da oposição entre personagens representados por máscaras, coreografias e versos formulares próprios, o contexto dos rituais dionisíacos teria moldado a poesia jâmbica segundo o padrão narrativo da oposição entre elogio e invectiva, o qual emergiria no duelo entre Páris e Menelau em Il. 3, 340-448. É particularmente revelador dessa perspectiva o emprego do adjetivo gynaimanés exclusivamente em relação a Páris nas duas únicas ocorrências do poema em Il. 3, 39 e 13, 769 e em relação a Dioniso no Hino homérico a ele (verso $8 \mathrm{ed}$. West)..$^{33}$

\footnotetext{
${ }^{31}$ Suter (1993, p. 9): "Two of the three Homeric figures whom Page mentions here as being described in the 'Archilochean', 'iambic' manner (Iros and Thersites) are abusers and objects of abuse in the narrative of the Homeric poems. And the 'detailed and highly specialized vocabulary, including numerous hapax eiromena', is precisely what the analysis of diction has just shown to exist for the name Paris. As we have noted, Thersites and Iros and Paris all have roles which involve blaming, being blamed and creation of conflict; the episodes in which they are involved follow similar patterns and reflect, perhaps, a stock pattern in the iambic repertory." 'Traduzi o verbo em inglês 'abuse' por 'ofender' em função do presente contexto, mas 'maltratar', 'agredir' e 'violentar' também seriam traduções possíveis. 32 Suter (1993, p. 9): “The existence of stock roles seems likely. It is not necessary for the present purpose to argue the question of stock characters; stock roles of the very basic kind which I have outlined in the narrative patterns found in Paris, Thersites and Iros episodes suffice. The specific subject matter of the abuse the figures offer and suffer varies; it is the roles and patterns of abuse which are standardized."

${ }^{33}$ Suter (1993, p. 13-15; em especial p. 15): "Most of the epithets surrounding the name Paris, then, may be associated with Dionysos." [...] [the poet] is, I suggest, introducing elements - epithets, diction, narrative patterns - from iambos, characterizing the Trojan prince of epic in a new way, as a blame figure, in the mould of Dionysos."
} 
Feitas essas considerações, caberia tentar definir qual das duas ocorrências de makblosínè seria a mais antiga, a iliádica, a respeito de Helena, ou a hesiódica, sobre as filhas do rei Preto. Como diferença mais significativa entre as duas versões, lembremos que apenas a lascívia das filhas de Preto é apresentada como uma punição divina, seja à pretensão de superar Hera em beleza seja à negligência com o culto de Dioniso, em ambos os casos no horizonte da temática da býbris. Tal como introduzida no canto 24 da Ilíada, a lascívia de Helena não é diretamente relacionada com nenhuma transgressão.

\section{A makhlosínē no julgamento de Páris}

Algumas observações sobre Helena nos ajudarão a circunscrever a perspectiva da Ilíada. Consideremos inicialmente as duas ocorrências do substantivo neutro plural hormémata relativamente a ela. Na primeira delas, Nestor encoraja Agamêmnon e os chefes aqueus lembrando-lhes dos juramentos que fizeram e dos sinais favoráveis que alega terem sido enviados por Zeus:

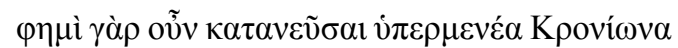

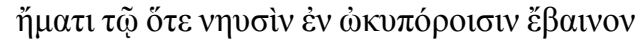

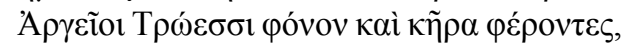

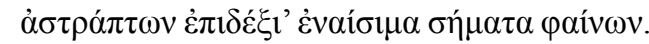

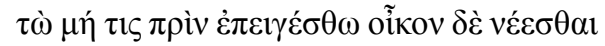

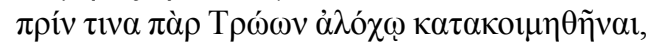

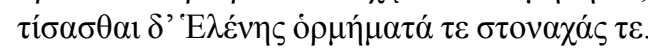

Pois digo ter acenado o Cronida de supremo ardor no dia em que os aqueus adentraram as naus de rápida travessia, aos troianos assassínio e morte levando, relampejando para a direita e sinais do destino mostrando. Portanto, que ninguém se apresse em voltar para casa antes de estender-se ao lado de alguma esposa dos troianos e de obter reparação pelos arroubos e lamentos de Helena! (Il. 2, 350-356) $)^{34}$

Mais à frente no mesmo canto, Menelau é mencionado no catálogo das naus:

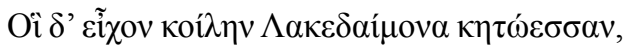

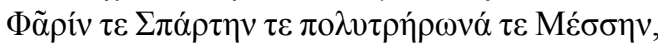

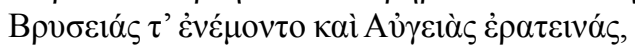

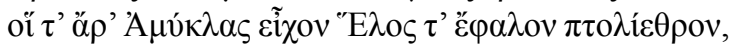

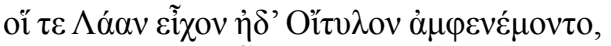

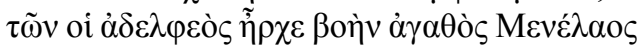

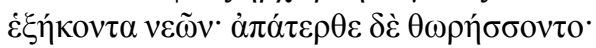

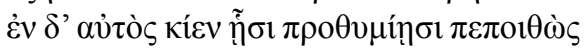

$\overline{{ }^{34} \text { Ver Il. 2, 337-368 }}$ para toda a fala de Nestor. 


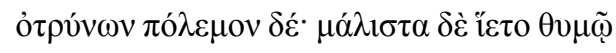

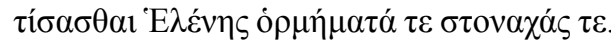

E os que tinham a côncava Lacedemônia de feras marinhas, Faris e Esparta de muitos sulcos e Messe, Brusseias ocupavam e Augeia amável e os que Amiclas tinham e Helos a cidade sobre o mar e os que tinham Laas e por Oítilo habitavam, deles comandava o bom ajudante Menelau sessenta naus; à distância armavam-se; ele próprio ia na sua impetuosidade confiante e incitando à guerra: pois desejava ao máximo em seu coração obter reparação pelos cuidados e lamentos de Helena. (Il. 2, 581-590)

Traduzo o neutro plural hormémata por 'cuidados', seguindo a interpretação que supõe o termo ser derivado do verbo hormaínō (nas ocorrências em que significa 'lançar na mente', com o sentido metafórico de 'preocupar-se com'), interpretando-se a flexão de Helénés como um genitivo objetivo, no sentido de "preocupações causadas por Helena". Mas, como nota o léxico de Liddell; Scott; Jones (1990, s.v.), também é possível interpretar hormémata a partir de hormáomai ('pôr-se em movimento', 'lançar-se') e considerar Helénès um genitivo subjetivo, dando à expressão o sentido de "impulsos de Helena". ${ }^{35}$ Esta segunda interpretação daria à rainha espartana uma participação ativa no adultério. Entretanto, ainda mais importante do que a atribuição ou não de alguma responsabilidade a Helena é perceber a ambiguidade com que o poema a caracteriza nessa e em outras passagens.

Ao surgir no canto 3, Helena já não parece mais envolvida eroticamente com Páris, obrigando Afrodite a ameaçá-la para promover o encontro do casal. ${ }^{36}$ Essa autonomia de seu desejo em relação à deusa sugere que, inversamente, também no passado ela se teria envolvido com Páris por iniciativa própria, ainda que apoiada pela deusa. A verdadeira miseen-scène pela qual Afrodite ampara as ações do príncipe troiano no canto 3, reafirmando sua predileção por ele, alude à intriga nuclear da guerra, aqui mimetizada em escala reduzida. Furtando-se às consequências da derrota no duelo, Páris ofende o cerne da honra heroica em que se baseia a moral agonística homérica. ${ }^{37}$ Acontecendo logo após a derrota para

\footnotetext{
${ }^{35}$ Liddell, Scott, Jones (1990), s.v. ő $\mu \eta \mu \alpha$. Ver também Cunliffe (1963, s.v.). A segunda interpretação pela qual ö $\rho \eta \mu \alpha$ é derivado de ó $\mu \alpha \dot{\omega} \omega$ - é favorecida pelo emprego exatamente desse verbo a respeito de Helena em Ilíada, III, 141-142: "Logo envolta em alvos tecidos / lançou-se (bormât'[o]) do quarto,

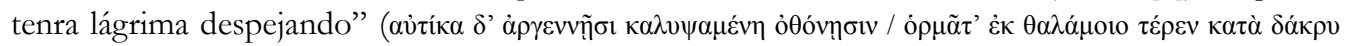

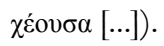

${ }^{36}$ Il. 3, 373-420.

${ }^{37}$ Páris se comporta de forma repreensível quando foge ao ver Menelau (Il. 3, 15-37), vindo a ser posteriormente recriminado por Heitor (Il. 3, 38-57), o qual, por sua vez, demonstra seu total comprometimento com a guerra ao recusar a Andrômaca sua proposta de juntar-se a ela abandonando temporariamente o combate (Il. 4, 404-439, em especial 429-439). Kirk (1978, p. 26-7) comparou o
} 
Menelau, a indiferença de Helena em relação a seu marido troiano se manifesta logo após a demonstração do descompromisso deste com o combate às portas de sua cidade. ${ }^{38}$ Em vez de alegrar-se com a surpreendente sobrevida do marido, Helena o reprova implacavelmente: "Vieste da guerra: quem dera pereceres lá mesmo / por um homem poderoso dominado, o qual era meu primeiro esposo!" ${ }^{39}$ Nas mais severas palavras proferidas por Helena em todo o poema, o desejo da morte do atual esposo pelas mãos do anterior exprime não apenas a vontade de Helena de punir Páris por seu descompromisso, mas também de desfazer por completo sua união com ele, como se fosse possível desfazer o já vivido, voltar no tempo.

$\mathrm{O}$ contraste entre o deleite amoroso induzido por Afrodite e o mundo da guerra é intensificado ao final da cena, que mostra Menelau à procura de Páris para que o duelo prossiga (Il. 3, 448-450). Assim, a suscetibilidade do príncipe aos encantos imediatos de uma 'lascívia (feminina)' estaria em consonância com seu comportamento menos engajado na vida guerreira e protegido por uma deusa alheia aos valores da guerra, embora não às consequências para o casal protegido. ${ }^{40}$ Ainda que a situação do final do canto 3 não passe de mais um encontro erótico do casal, é o único entre mortais efetivamente indicado no presente da narrativa. Seu viés marcadamente negativo contribui significativamente para a sombria atmosfera que continuará pesando sobre as relações humanas até o final do poema.

Mas se no canto 3 Afrodite precisa coagir sua protegida a deitar-se com Páris, a própria Helena se insinuará ao cunhado pouco depois, quando este apresentar-se no quarto do casal à procura do irmão:

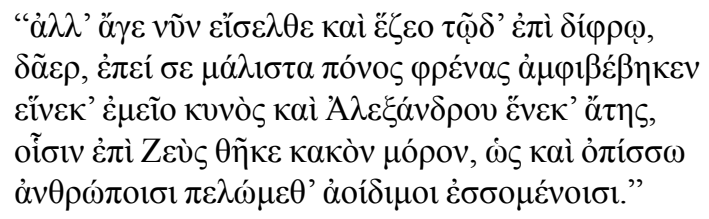

"Vem, adentra e senta-te nesta banqueta, cunhado, uma vez que o trabalho constrange ao máximo tua inteligência por causa de mim, esta cadela, e por causa da demência (átê) de Alexandre, aos quais Zeus impingiu maligno destino, para que também futuramente

comportamento dos dois: "Paris is boastful and volatile, not always very brave but much impressed by Hector, hence his initial bravado and subsequent stiffening under rebuke. Menelaus is a good fighter, not one of the very best but keen to come to grips with his personal enemy at any opportunity. The only question is why the poet makes him defeat Paris so easily after the first exchange of spear-throws. Perhaps it is because he is the right, and therefore protected by Zeus despite the god's undertaking to Thetis. It is fitting in any event that such warriors as these, as protagonists of the quarrel, should be more impressive in their preparation and oaths than in the duel itself."

${ }^{38}$ Il. 3, 59-82.

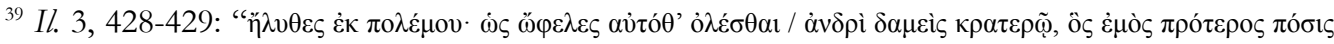
$\tilde{\eta} \varepsilon v "$. O desprezo de Helena por Páris caracteriza toda a fala (Il. 3, 426-436).

${ }^{40}$ Não é certamente sem importância, dada a natureza de sua esfera de ação (timée), que Afrodite seja a única deusa homérica a proteger simultaneamente dois mortais. 
aos humanos vindouros tornemo-nos tema de canto." (Il. 6, 354-358)

A impotência dos encantos de Helena diante do tenaz compromisso de Heitor com a defesa de Troia destaca o contraste entre as duas esferas da convivência humana, o erotismo e a guerra, bem como seus frequentes e catastróficos vínculos na tradição épica (as guerras pelas conquistas de Tebas e de Troia ou envolvendo a participação dos maiores heróis, como Héracles ou Teseu). ${ }^{41}$

Esse significativo encontro entre Heitor e Helena também remete ao paralelismo entre ela e Aquiles, cada qual incorporando uma das duas esferas, guerra ou erotismo, na sua expressão mais extrema:

Ela coloca seu próprio senso de vergonha, seu próprio arrependimento acerca de sua existência e a indignação que ela gerou em outros em contraste com a despreocupação de seu marido: seu propósito é angariar a simpatia de e conectar-se com Heitor, exibirlhe sua consciência da tensão que elas [scil. a vergonha e a indignação] o fazem suportar. [...] Heitor claramente não está conectando-se com a longa visão, cósmica e poética, que Helena lhe oferece. Aparentemente, nada poderia estar mais distante da mentalidade de um guerreiro há pouco envolvido em um combate e ávido por retornar a ele, e é por isso que a fala de Helena que procura simpatia fracassa. [...] Mas o paralelo entre a canção de Aquiles em Ilíada, IX, embora seu tema não seja dado, e a atividade de tecelagem de Helena, cujo tema são as labutas dos troianos e dos aqueus, é gritante, e ele marca os dois personagens como relacionados mas também isolados na perspectiva, para não dizer a distância, que eles adquirem dos sofrimentos à sua volta. ${ }^{42}$

Para Mayer, o nascimento de Aquiles, embora mencionado apenas discretamente na Ilíada, seria um elemento decisivo não apenas para a trama principal do poema, mas também

\footnotetext{
${ }^{41}$ West, 2003, p. 4-16, e 2013, p. 13-9.

${ }^{42}$ Muellner (2016, online sem numeração de página): "She sets her own sense of shame, her own regret about her very existence and the indignation that she has generated in others in contrast to the insouciance of her husband: her intent is to ingratiate herself and connect with Hektor, to exhibit to him her awareness of the stress that they cause him above all to bear. [...] Clearly Hektor is not connecting to the long view, cosmic and poetic, that Helen offers him. Apparently, nothing could be further from the mindset of a warrior just now engaged in combat and eager to return to it, and that is why Helen's otherwise ingratiating speech fails. [...] But the parallel between Achilles' song in Iliad 9, though its subject is not given, and Helen's weaving, whose subject is the toils of the Trojans and the Achaeans, is striking, and it marks the two characters as related but also isolated in the perspective, not to say the distance, that they acquire from the sufferings around them."
} 
para todo o mito da guerra de Troia. ${ }^{43}$ Acrescente-se a isso que Aquiles e Helena aparecem associados em cultos religiosos do período arcaico. ${ }^{44}$

O estreito e tenso vínculo entre erotismo e guerra é parte integrante da narrativa da Ilíada, dada a importância do erotismo em torno de Helena, precedendo e motivando a guerra. Esse vínculo reaparecerá de forma igualmente indissociável na disputa entre Aquiles e Agamêmnon por Briseida, que desencadeará a contenda entre os dois heróis e redefinirá a guerra. ${ }^{45} \mathrm{Em}$ um dos estudos mais abrangentes sobre a composição dos personagens da Ilíada, Collins (1988) destacou a importância da temática da indignação (némesis), da cólera (khólos) e da 'dor moral' (ákhos) nos conflitos em torno da honra heroica ao longo do poema, tais como afetam e contrapõem Agamêmnon, Aquiles, Páris e Heitor. Em meio à tensão entre essas emoções, a oposição entre o erotismo e a guerra é assim caracterizada:

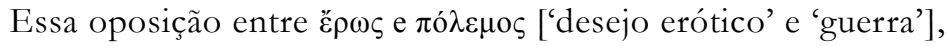
bem como suas respectivas identidades éticas, é maior do que a caracterização de Páris e atravessa toda a Ilíada. A imagética marcial do poema se vale de empréstimos da perseguição erótica e de outras perseguições não-marciais (p. ex. $\mu \dot{\varepsilon} \lambda \pi \varepsilon \sigma \theta \alpha \iota$ 'Ap̣n ['dançar por Ares'], Il. 7,241 ) e, igualmente, o relacionamento erótico é expresso como uma batalha lutada entre fracos (p. ex. Il. 5, 348-351). Entretanto, o poema

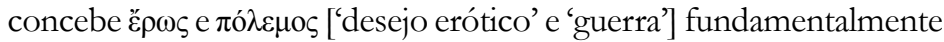
como definindo esferas opostas e separadas, como é explicitado ao máximo na sua apresentação de Afrodite. Zeus define explicitamente

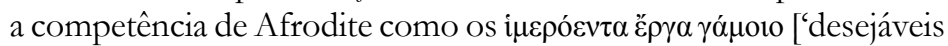
obras do casamento'] e opõe esses aos $\pi$ o $\lambda \varepsilon \mu \eta \dot{1 \alpha}$ है $\rho \gamma \alpha$ ['obras da guerra'], que são, ele diz, a província de Ares e de Atena (Il. 5, 4279). Diomedes, encarando Afrodite no campo de batalha, insinua que

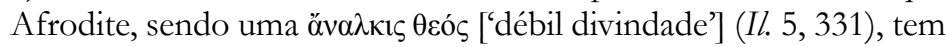

\footnotetext{
${ }^{43}$ Mayer, 1990, p. 2-3: "The original scholium does not define the precise role of the $\theta v \eta \tau$ royaía of Thetis. That marriage resulted indirectly in the judgment of Paris and the strife between the goddesses, which directly led to the Trojan War. Eustathius, who was rather closer to the scholiastic tradition than we are, does not include the judgment in this account of the origins of the war. Instead he regards the birth of Achilles as a central element in the depopulation of mankind, on par with Helen." ${ }^{44}$ Austin (1994, p. 26-7, n. 4) nos lembra, a propósito, dos cultos aos heróis no período arcaico, especialmente dos cultos de Helena e de Aquiles. A esse respeito, ver sobretudo West (1997, p. 230): "In the epic tradition Helen appears as a mortal queen at Sparta who by eloping with Paris caused a huge and disastrous war. But in Laconia she was worshipped as a goddess, and so she was on Rhodes, where Helios too was a major deity. The cults can hardly have grown out of the epic myth; rather Helen was a goddess from the start. By blaming her for the Trojan War the poet Stesichorus, according to legend, offended her and she struck him blind, later restoring his sight after he had composed a palinode. In a variant of the story (Horace, Epod. 17.42) it was the Dioskouroi who blinded and then healed him. In either case it is noteworthy that restoring sight to the blind is a typical accomplishment of the Ashvins."

${ }^{45}$ Ver nota 10 supra.
} 
expectativas reduzidas contra ele, enquanto ela se sairá bem se tiver a sorte de superar mulheres ảvó $\lambda \kappa \iota \delta \varepsilon \varsigma$ ['débeis'] pela sedução (348351). Esse é o modo com que Helena também descreve a técnica e a orientação de Afrodite, quando ela a reprova por intervir a favor

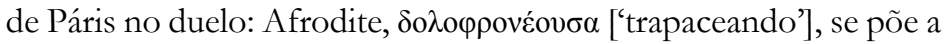

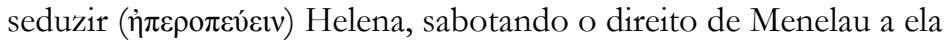
pela ví́n ['vitória'] (Il. 5, 399, 404f.). ${ }^{46}$

A oposição entre o deus da guerra e a deusa do erotismo acontece entre suas respectivas esferas de ação, cada esfera emanando de um corpo divino próprio: atração recíproca de um lado, incompatibilidade total de outro. A inaptidão de Afrodite para o confronto físico a desqualifica a priori para auxiliar em uma guerra de que outros deuses participam, a não ser - como no resgate de Páris - para retardá-la.

Em consonância com essas características da deusa, as motivações eróticas se mostrarão incapazes de interferir nos rumos da guerra ou de anular suas terríveis consequências, tanto no que diz respeito a Helena quanto a Briseida, para ficar apenas na trama principal. Também Helena ficará em segundo plano em relação a Aquiles, aparecendo sobretudo como vítima dos efeitos que, à sua revelia, a beleza tem sobre os homens. Tem sido muito comentada a esse respeito a observação dos anciãos troianos na teikhoskopía:

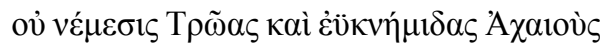

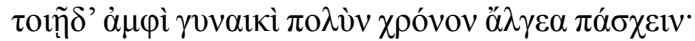

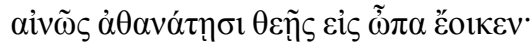

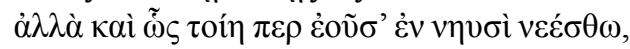

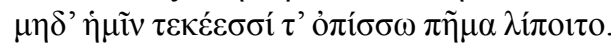

Não é de indignar os troianos e os aqueus de belas grevas por uma tal mulher por muito tempo sofrerem dores:

assustadoramente seu rosto se assemelha às deusas imortais!

Mas mesmo ela sendo assim, que volte nas naus,

\footnotetext{
${ }^{46}$ Collins (1988, p. 36): “This opposition between $\check{\varepsilon} \rho \omega \varsigma$ and $\pi$ ó $\_$$\mu$ os, as well as their respective ethical identities, are larger than the characterization of Paris and run throughout the Iliad. The poem's martial imagery borrows from erotic and other nonmartial pursuits (e.g., $\mu \varepsilon \dot{\lambda} \pi \varepsilon \sigma \theta \alpha \mathrm{l}$ 'Apๆ, H 241) and, likewise, the erotic relationship is expressed as a battle fought between weaklings (e.g. E 348-351). Yet the poem fundamentally conceives of $̌ ́ p \omega \varsigma$ and $\pi$ ó $\lambda \varepsilon \mu \circ \varsigma$ as defining separate and opposing spheres, as is most explicit in its presentation of Aphrodite. Zeus explicitly defines Aphrodite's expertise as

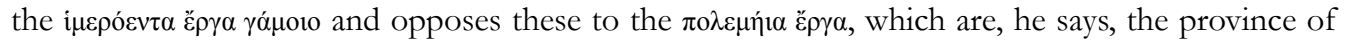
Ares and Athena (E 427-9). Diomedes, facing Aphrodite on the battlefield, implies that Aphrodite,

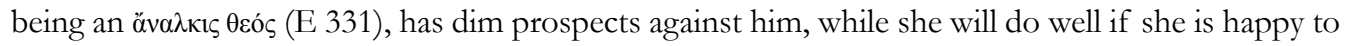
overcome àvó $\lambda \kappa \imath \delta \varepsilon \varsigma$ women by seduction (348-351). This is the way Helen also describes Aphrodite's technique and orientation, when she reproaches her for intervening on Paris' behalf in the duel:

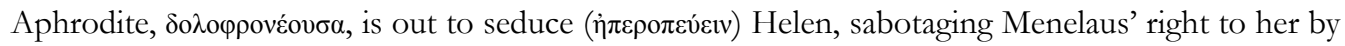
víкп (Г 399, 404f.)." 'Traduzi 'overcome' por 'superar', mas 'vencer' seria uma alternativa possível, complementar à primeira.
} 
para que posteriormente não reste uma catástrofe às nossas progênies! $(\text { Il. } 3,156-160)^{47}$

A beleza de Helena não é 'de indignar' (ou némesis), mas não deixa 'de assustar' (ainôs): os homens que, pelo peso da idade, já não se abalam mais tanto com sua presença, compreendem-na sem exasperação; amedrontam-se, contudo, ante as inevitáveis consequências que atingirão, finalmente, a todos. Tal condição leva Helena a manter a reserva ao relacionar-se com a corte troiana, embora sem indiferença: aceita resignadamente as consequências de sua presença, como se as tivesse previsto. Não somente suas palavras, mas também sua impassividade diante da guerra sugerem uma compreensão trágica do próprio destino. $^{48}$

O mistério em torno de Helena se desfaz aos poucos, no presente da narrativa, através dos relances do passado insinuados pelo comportamento atípico de Páris entre os guerreiros troianos. Expõe-se a fragilidade do vínculo entre o casal, que não decorreu da admiração dela pela virilidade (ènoréé) dele, de onde nasceria a glória da vitória no combate - como, emblematicamente, no caso de Belerofonte. ${ }^{49}$ Correspondendo à sensualidade de Helena, Páris está frequentemente alheio aos desdobramentos da guerra e espelha, a

${ }^{47}$ Cf. Ilíada, III, 121-244, para a teikhoskopia, e 121-60, para toda a fala dos anciãos. A respeito da oposição arquetípica entre o erotismo de Helena e a índole belicosa de Aquiles, lembremo-nos de que Nagy (2005, p. 81-2) chamou a atenção para a diferença entre o Aquiles mais erotizado da Etiópida, de Arctino de Mileto, ilha jônica com contato com as cidades eólicas de Lesbos e da costa da Ásia Menor, e o Aquiles homérico, mais sóbrio e obcecado pela guerra.

${ }^{48}$ A impassividade altiva e trágica de Helena, como filha de Zeus e centro da motivação da guerra, foi ressaltada com muita agudeza no comentário de Rousseau (2003) sobre a cena em que ela aparece tecendo um véu (Il. 3, 125-128), cujo desenho é apenas referido genericamente, sem ser propriamente descrito. Chamando a atenção para a persistência da metáfora têxtil na poética dos aedos (op. cit., p. 14), o autor analisa as circunstâncias em que a atividade de tecelagem de Helena aparece - quando Íris vem lhe avisar do duelo prestes a acontecer entre Páris e Menelau (Il. 3, 121-124) - e propõe que a cena se relaciona com a participação dela na origem da guerra (op. cit., p. 37): "Le plan, ou la mètis, qui gouverne secrètement le tissage de l'épouse conquise, et reconquise, par Pâris, est celui qu'a conçu et que poursuit Zeus. Les épreuves dont la tisserande parsème sa toile sont celles que la boulè de Zeus impose aux Troyens et aux Achéens, le lot de 'souffrances et de plaintes' que le dieu leur a assigné pour leur perte. Voulues par lui elles dessinent, produisent, l'histoire que l'aède prend comme matière de son chant. [...] Hélène ne 'raconte' pas dans sa toile l'histoire dont Homère fait le récit dans son chant, elle la crée." A dimensão trágica da trama central da Ilíada, em particular no que diz respeito a Aquiles, foi proposta em toda a sua riqueza por Rutherford (1982), que salientou a determinação de Aquiles a levar suas decisões até as últimas consequências, em detrimento de todo o sofrimento causado a outras pessoas e a si mesmo.

${ }^{49}$ Il. 6, 155-157: "Então Glauco gerou o impecável Belerofonte; / a ele os deuses fizeram seguir

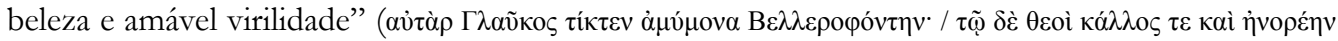

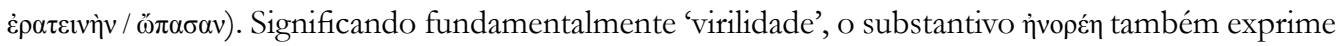
a coragem que se manifesta na existência guerreira que se coloca como o principal modelo social do homem jovem em Homero. 
seu modo, a feminilidade de Afrodite. ${ }^{50}$ Enquanto a presença de Páris na linha de frente é flagrantemente menos frequente do que se espera, é justamente a presença de Helena que perturba, por representar ao mesmo tempo a afronta à honra dos aqueus e a origem dos intermináveis sofrimentos dos troianos. ${ }^{51}$

Para ser aceita pelos homens da corte troiana, Helena se reabilita através de frequentes declarações de auto-acusação, conforme ressaltado por Collins (1988) e por Ebbott (1999)..$^{52}$ Mais recentemente, a mesma linha de interpretação foi retomada com ainda maior refinamento por Blondell (2010), que percebeu o jogo entre masculinidade e feminilidade na relação da corte troiana com Helena, e observou:

${ }^{50}$ Collins (1988, p. 37-8): "This poem focused on war periodically invests the nexus of themes with which Paris is identified with an according ethical value of $\alpha$ a grieving for the death of Hector and his other warrior sons (

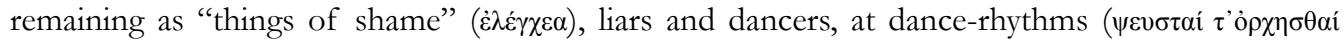

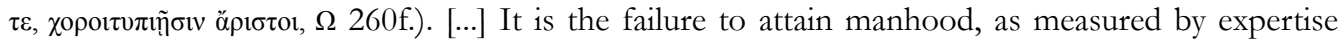
in the $\pi \circ \lambda \varepsilon \mu \eta$ í $\_$है $\gamma \alpha$, which creates the personality which is most conducive to the ascendance of

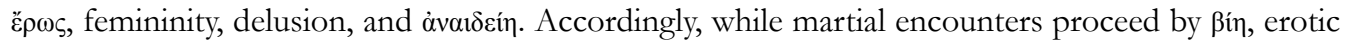

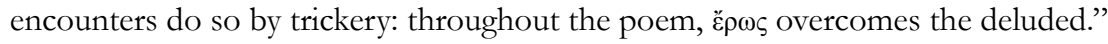

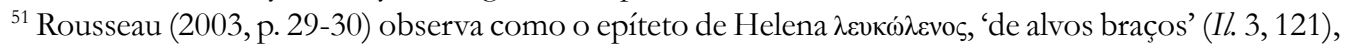
bem como toda a caracterização dela como esposa de Menelau, ressaltam sua posição problemática tanto para a sociedade dos troianos quanto para a dos aqueus: "Elle tisse comme le veut son devoir de femme. Mais pour cette raison même son tissage, dans le megaron où elle se tient, c'est-à-dire, dans le palais de Pâris, est une expression symbolique de ce qui est à l'origine de la guerre et des épreuves endurées par les Troyens et les Achéens."

${ }^{52}$ Collins (1988, p. 45): "First, the marriage of Helen and Paris is a subject of public reproach precisely because it challenges those very values of pi $\lambda$ óm repeatedly eulogized in the Iliad. [...] Second, as we have noticed, the blame of Helen is always selfblame. The Iliad does not depict direct blame of her by the Achaeans or Trojan pínor, leaving it to Helen herself to fix blame on Helen for the grief of war. Indeed it is Helen who is made to bear sole witness to the way in which the dominant community views her. And Helen is made to agree with them, to embrace the orthodox values against which she once transgressed; she is thus made to reject the ethics of her patroness and thus of her own identity." Sobre esse tema da 'autoacusação' - ou, em outra tradução, 'autoinculpação' - de Helena ('self-blame'), ver Ebbott (1999), que afirma que "her character is defined by both shame and nemesis" (p. 5) e destaca as semelhanças entre o gênero do discurso de lamentação e as falas de Helena. Se, como vimos acima, os anciãos da corte troiana não se indignam (Il. 3, 156-157) ao ver Helena, ela própria incorpora essa indignação (némesis) acerca de suas ações no passado, através das características da lamentação tradicional (p. 17 e 19): “The blame that perhaps existed in a contemporary poetic tradition, and that surely would have existed in some story of Helen and Paris, has been displaced from a community reaction of nemesis to Helen's own self-blame. [...] Although the war may provide the opportunity for kléos, 'glory, renown', for those fighting over Helen, nemesis still attends the war because of and through Helen herself.' 
É claro que ela poderia ter protegido seu próprio $\kappa \lambda \hat{\varepsilon}$ os representandose como um objeto roubado, como fazem os homens, salvando assim sua cara - para não falar de seu pescoço - por colaborar na sua própria objetificação. Em vez disso, ela escolhe se autoacusar. Além de lhe servir como uma estratégia retórica, essa autodepreciação também é uma asserção de agenciamento no passado. Como tal, ela forma parte de uma perspectiva helênica coerente sobre a fuga original. Onde outros acusam somente Páris, Helena os liga como conjuntamente responsáveis por suas transgressões, colocando implicitamente seu agenciamento na mesma base (Il. 6, 356-58). Seus desejos repetidos de que tivesse morrido antes de toda a celeuma ter começado (Il. 3, 173-75; 6, 344-51; 24, 764) ecoam os desejos de Heitor, e seus próprios, em relação a Páris (Il. 3, 40; 3, 428-29; cf. também 6, 280-85), e funcionam semelhantemente como um modo de atribuir responsabilidade pelo comportamento vergonhoso. Ela é a única pessoa a usar verbos ativos para a sua parte na fuga, dizendo que ela 'seguiu' Páris (غ̇лó $\mu \eta v)$, 'deixando' sua família anterior

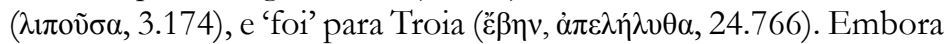
esses verbos não provem agenciamento voluntário - pode-se 'ir' sob pressão - no canto 3 , o contexto deixa claro que ela foi impelida por seu próprio desejo. 'Se somente eu tivesse tido prazer na morte' (Il. 3, 173) sugere, 'Se somente eu tivesse desejado morrer em vez de desejar o que eu desejei.' A dicção de sua autoacusação reforça esse sentido dela mesma como um agente (destrutivo). A metáfora da

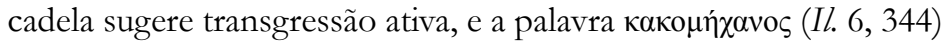
sugere agenciamento poderosamente destrutivo. [...] Sua aceitação de responsabilidade é, dessa forma, um ato de desafio. Como tal ela permite ao poeta ter o bolo e comê-lo, fazendo de Helena uma 'boa' mulher e, assim, pela qual vale a pena lutar, mas também condenável, apresentando-a como um objeto precioso mas passivo dos desejos dos homens, e também permitindo-lhe uma medida de subjetividade e agenciamento (retrospectivo). Uma vez instalada em Troia, ela é redomesticada como uma boa esposa que tece e serve o leito de seu marido. Mas através de sua autoacusação ela retém um traço da autoasserção que ela exerceu em sua fuga original..$^{53}$

\footnotetext{
${ }^{53}$ Blondell (2010, p. 14-6): "She could, of course, have protected her own $\kappa \lambda \dot{\varepsilon}$ o a plundered object, as the men do, thus saving her face-not to mention her neck-by collaborating in her own objectification. Instead, she chooses to blame herself. Besides serving her as a rhetorical strategy, this self-deprecation is also an assertion of past agency. As such, it forms part of a coherent Helenic perspective on the original elopement. Where others blame only Paris, Helen links them as jointly responsible for their transgression, implicitly placing their agency on an equal footing (6.356-58). Her repeated wishes that she had died before all the trouble started (3.173-75, 6.344-51, 24.764) echo Hector's wishes, and her own, regarding Paris (3.40, 3.428-29; cf. also 6.280-85), and serve similarly as a way of assigning responsibility for shameful behavior. She is the only person to use active verbs
} 
A atuação de Afrodite na formação do casal Páris-Helena mostra o que resulta de um desequilíbrio na oposição entre guerra e erotismo. ${ }^{54}$

$\mathrm{Na}$ esteira do clássico estudo de Reinhardt $\left(1938^{1}\right.$; reimpr. 1960), Davies (2003) sublinhou os elementos que sugerem a origem folclórica da trama do julgamento de Páris, mostrando como a Ilíada a incorpora em uma narrativa que transforma o herói em um transgressor. ${ }^{55}$ Por sua vez, essa transformação adquire ainda maior importância por aparecer na Iliada como parte da luta pelo poder supremo, no contexto de um mito de sucessão divino, no qual, segundo a versão tradicional do oriente próximo, a humanidade teria nascido do deus derrotado por aquele que se tornou o rei definitivo (mas isso não é explicitado em Homero nem nas demais versões gregas). ${ }^{56}$ Também como consequência dessa luta pelo

for her part in the elopement, saying that she "followed" Paris (غ̇ंó $\mu \eta v)$, "leaving" her former family

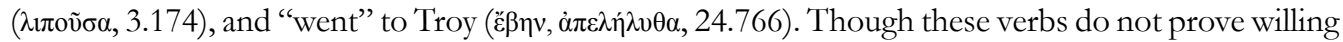
agency-one may "go" under duress—in Book 3, the context makes it clear that she was impelled by her own desire. "If only I had taken pleasure in death" (3.173) implies, "if only I had desired to die instead of desiring what I did desire." The diction of her self-blame reinforces this sense of herself as a

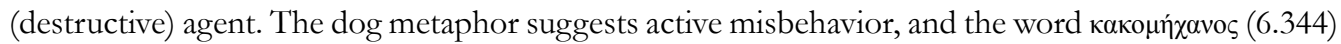
implies powerfully destructive agency. [...] Her acceptance of responsibility is, in its way, an act of defiance. As such it enables the poet to have his cake and eat it, making Helen a "good" woman and thus worth fighting for, but also blameworthy, presenting her as a precious but passive object of men's desires, while also allowing her a measure of subjectivity and (retrospective) agency. Once installed at Troy, she is redomesticated as a good wife who weaves and serves her husband's bed. But through her self-blame she retains a trace of the self-assertion that she exercised in her original elopement." ${ }^{54}$ Sobre a relação entre o erotismo e a guerra no período clássico ver o capítulo de Loraux, 'Le lit, la guerre' (1989, p. 29-53).

${ }^{55}$ Davies (2003, p. 36-7): "The vestiges of an original folk-tale may be here detectable, just as (on Uvo Holscher's showing) they may be detectable in the next major episode of the same epic, when, once again very consistently with the Proppian scheme, an act of 'villainy' ( Paris' act of betrayal) precipitates an initial 'lack' (specifically of Helen), which in turn unleashes the heroic quest which is the Greek expedition to Troy. However, the juxtaposition of these two folk-tale sequences within the Cypria reminds us of some of the complexities involved: if Paris is formally the 'hero' of the first sequence, he is the 'villain' of the second. It is perhaps in keeping with this paradox that the 'reward' from Aphrodite, the gift that expedites Paris' quest, should, according to the Iliad's account, be something so ambivalent as $\mu \alpha \chi$ o mitológicos gregos e desenvolve o tema relacionando o fato de a lascívia ter sido um dom de Afrodite na Ilíada com as narrativas a respeito do dom do canto oferecido pelas Musas a Hesíodo e a Arquíloco em suas obras e biografias. O tema da perigosa ambivalência do dom divino já havia sido explorado a respeito do dom das Musas na Teogonia de Hesíodo por Pucci (1977, p. 25-6).

${ }^{56}$ Mayer (1990, p. 4): "Central to the larger construct is the final struggle for heavenly succession, in which the last opposition to the canonical pantheon is quelled. The creation of man is contemporaneous with or results from this struggle. Often the defeated god or gods are involved in the creation of mankind in general or of a particular strife-causing individual or group. The form of the defeated gods' involvement varies: mankind may be their direct progeny, their creations or reincarnations, or created from their body parts or secretions." 
poder, a humanidade seria assolada por uma terrível catástrofe, gerada para a punição de seus abusos em relação aos deuses..$^{57}$

\section{Considerações finais: a poÉtica das emoções singulares na Ilíada E a PLAUSIBILIDADE DE UMA MAKHLOSÝNẼ DE HELENA}

O modo breve das referências a algumas emoções ao longo do poema se insere na rica trama de alusões diretas ou indiretas, mais ou menos extensas, que caracteristicamente compõem os poemas homéricos. São diversas histórias narradas ou simplesmente mencionadas, paralelamente à trama principal, remetendo ao passado dos personagens, principais ou secundários, ou de seus antepassados, ou, ainda, a exemplos ilustrativos de alguma lição de vida..$^{58}$

Mencionada uma única vez nos poemas homéricos, a makblosýnē de Helena a coloca no centro de uma trama que não apenas já se teria iniciado anteriormente aos acontecimentos narrados na Ilíada como também comporia, com as emoções que vieram a afligir Agamêmnon, Páris e Aquiles, o que se pode chamar de cadeia emocional da trama principal. Por sua vez, a lascivia deve ser considerada uma causa anterior e determinante da

\footnotetext{
${ }^{57}$ Mayer (1990, p. 7-8): “In these mythologies, a disaster befalls mankind which becomes a permanent facet of mankind's existence and solves overpopulation. This disaster is often the result of the impure creation of mankind, which is in turn a consequence of the final battle in the struggle for divine succession. The mention of overpopulation in the Cypria suggests that a similar pattern informs accounts of the origin of the Trojan War found in that epic and elsewhere. The scholiasts link Zeus' solution to overpopulation, the Diòs boule with the marriage of Thetis and the creation of Helen. As we saw earlier, the marriage of Thetis also marks the final resolution of the succession struggle in the heavens and its displaced continuation on earth. Achilles is therefore to be understood as a would-be successor, whose destiny has been foiled by the thnetogamia, the first part of the Diòs boulé. What then is the point of the second element of Zeus' plan, the creation of Helen, I propose that on some level Helen represents the flawed creation of man, or rather woman."

${ }^{58}$ Sobre as narrativas curtas da Ilíada ver Lang (1983) e sobretudo Scodel (2002, p. 124-154). Sobre o recurso à 'alusão' na Ilíada ver Slatkin (1995 [1991], cap. 4: 'Allusion and interpretation', p. 107122; em particular p. 108-111), que retoma a proposta de Lang, 1983: "We might say that allusions provide the coordinates that locate the poem's action within a multidimensional mythological realm. [...] There are, therefore, more layers of allusion than one, and in this sense the term 'reverberation' is particularly expressive. Digressions about divine disorder echo another clash; they refer us to the ultimate contest for cosmic rule. Allusions form a system of evocation in which each reference produces not a single meaning but a sequence of overlapping significations as with echoes, in which it is not the original sound but each subsequent iteration that is picked up and relayed. [...] Such allusions as this, intertwining divine and human interests, bind past and future in a continuum whose effect is to blur the boundaries between digression and the narrative proper and to show the poem reasserting those boundaries by taking stock of, or reflecting on, its own plot." Ver ainda Macleod (1982, ad Iliada, XXIV, 25-20, p. 88): "The curt and elliptical style is natural when, as here, a story is only mentioned, not told: cf., e.g. 9. 566-7; Od. 8. 76-82; also 608-9 n.”.
} 
demência (átê) de Agamêmnon, dando início à sequência catastrófica dos acontecimentos ao desencadear a demência de Páris e, por meio desta, a cólera (mênis) de Aquiles, conforme se pode representar no seguinte esquema:

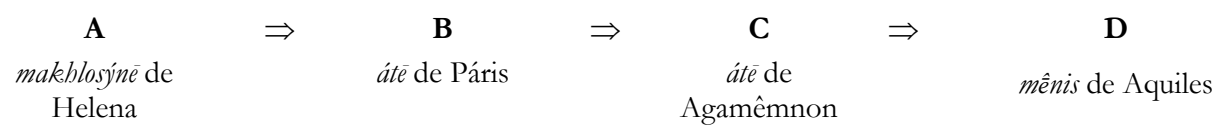

Atingindo personagens diferentes e em momentos diferentes de uma história que a Ilíada só recupera alusivamente e em flash-back, as três emoções serão eficazmente responsáveis pela mortandade visada pelo plano de Zeus: segundo o fragmento de um trecho dos Cípria, ele teria adotado a sugestão do deus Momo ('Censura' ou 'Reprovação'), que personifica o uso severo, intransigente da palavra (um deus do qual, todavia, não há vestígios em Homero)..$^{59}$

No que diz respeito à transmissão, espero ter mostrado que a discussão em torno do sentido e da autenticidade do emprego de makblosýné em Ilíada, 24, 30 revela o processo de formação de um 'gosto' antigo relativo aos poemas homéricos, particularmente no que diz respeito ao erotismo. Por se tratar de um poema cuja temática é predominantemente guerreira, sendo também ainda o expoente de uma tradição poética muito enfaticamente guerreira, uma referência tão direta e incisiva ao erotismo pareceu inadequada a Aristarco e a outros intérpretes da época, que se preocupavam com o estabelecimento de um texto inteiramente fiel ao que acreditavam ter sido a poesia 'homérica'.

No entanto, esses julgamentos sobre a poética homérica são questionáveis. Retomando nossa reflexão inicial sobre a influência da perspectiva moral posterior na recepção dos poemas homéricos, voltemos uma última vez a Dover (1974, p. 101-2):

Em contraste com as crenças curiosas propagadas no mundo falante de inglês durante os últimos cem anos ou algo parecido (condicionado à pressuposição de que a ausência de resposta sexual é moralmente louvável), os gregos eram inclinados a pensar que as mulheres desejavam e desfrutavam da relação sexual mais do que os homens. Andrômaca em Eurípides, Troianas 665ss. refere-se a uma crença ('dizem...') de que uma noite na cama dissolve a hostilidade de uma mulher em relação ao homem de que ela se tornou posse; cf. Eur. fr. 323 pelo contato físico mais do que qualquer outra coisa um homem 'adquire a alma de uma mulher'. ${ }^{60}$

\footnotetext{
${ }^{59}$ Cipria, fr. 1-5 West (West, 2003, p. 68-72).

${ }^{60}$ Dover (1974, p. 101-2): "By contrast with curious beliefs widely propagated in the English-speaking world during the last hundred years or so (conditioned by the presupposition that absence of sexual response is morally praiseworthy), the Greeks were inclined to think that women desired and enjoyed sexual intercourse more than men. Andromakhe in Eur. Tro. 665f. refers to a belief ('they say...') that one night in bed dissolves a woman's hostility to the man into whose possession she has come; cf. Eur.
} 
Crenças dessa natureza poderiam ter interferido na edição e na interpretação do personagem de Helena em diversos momentos da composição e transmissão da tradição homérica.

Levando-se em conta a relação entre o tom cômico das cenas que retratam a oposição complementar entre guerra e erotismo, bem como, por outro lado, a caracterização dionisíaca do casal Páris-Helena, três consequências podem ser elaboradas a respeito da referência à makblosíné no canto 24 :

(a) A vontade de Helena é colocada no centro da narrativa da trama do início da guerra e confirmada nas passagens em que ela aparece no poema, conforme destacado por Blondell (2010). Assim como Helena aparece poucas vezes ao longo do poema, também a makblosýnè seria reservada a um mínimo de ocorrências. ${ }^{61}$

(b) A makblosíne traz Páris novamente ao centro da narrativa, preparando sua atuação como assassino de Aquiles na sequência dos acontecimentos da trama da guerra de Troia.

(c) A partir de (a) e (b) pode-se ainda especular que a trama feminina sobre as mães dos heróis, que, na tradição hesiódica, sucede à trama masculina da Teogonia - no poema hexamétrico conhecido como Catálogo das mulheres -, poderia dar continuidade à história da guerra de Troia em um novo poema. Nesse caso, além da oposição entre narrativa com ênfase divina (a Iliada e a Teogonia de Hesíodo) e narrativa com ênfase humana (a Odisseia e os Trabalhos e dias), como sugerido por Burkert (2004, p. 24-5), teríamos ainda a oposição entre narrativa masculina e narrativa feminina nos corpora homérico e hesiódico. ${ }^{62}$

Essas hipóteses poderiam justificar tanto a antiguidade da ocorrência de makblosíné em Il. 24, 30, quanto sua inserção posterior por um poeta cuja interpretação da tradição homérica o houvesse ensejado a continuá-la com nova ênfase.

fr. 323 by bodily contact above all a man 'acquires a woman's soul'." Como exemplos principais o autor acrescenta Anandrides, fr. 60; Eurípides, Hipólito, 967-70; Isócrates, 10, 60; Eurípides, Medeia, 569-75. ${ }^{61}$ Mayer (1990, p. 7-8): "It seems that the drama culminated in the creation of Helen, and that this act, and no other, was felt to have led to war. Horace also indicates that the Cyclic poets took the creation of Helen to be the beginning of the Trojan War. For these poets the pivotal moment that led to the war was not a particular transgression on Helen's part, but her very creation. Like Pandora she is portrayed as being bad from birth, designed by Zeus to pass onto mankind the myriad of miseries which are their lot. The connection between Helen and the Diòs boulé is thus not an accident of scholiastic pedantry, but reflects part of the mythological tradition preserved in the Cypria."

${ }^{62}$ West (1966, p. 3): "For Hebrew literature, I need only refer to the opening chapters of Genesis, and remark that these lead directly on to the human genealogies, which, like the Hesiodic catalogues, account for the origins of peoples as well as of families. A myth of the union of gods and mortal women, producing heroes or giants, seems to lie behind Gen. VI. 1-4.1.” 
O EROTISMO DE HELENA NA ILÍADA: DIONISO, A PERSPECTIVA HOMÉRICA E O GOSTO

DOS COMENTADORES

\section{REFERÊNCIAS}

APOLLODORUS. The library. Cambridge, MA: Harvard University, 1946.

ASSUNÇÃO, T. R. O segundo riso dos deuses na canção sobre o amor de Ares e Afrodite (Odisseia 8. 325-345). In: OLIVEIRA, F. de; SILVA, M. F.; BARBOSA, T. V. R. (Coord.). Violência e transgressão: uma trajetória da Humanidade. Coimbra; São Paulo: Imprensa da Universidade de Coimbra; Annablume, 2014, p. 59-77.

AUSTIN, N. Helen of Troy and her shameless phantom. Ithaca, London: Cornell University Press, 1994.

BARBOSA, T. V. R. Rir por pura crueldade. In: KANGUSSU, I. et al. (Org.). O cômico e o trágico. Rio de Janeiro: 7Letras, 2008, p. 89-105.

BENVENISTE, E. Le vocabulaire des institutions indo-européennes. Paris: Éditions de Minuit, 1969. t. 2.

BLONDELL, R. "Bitch that I Am". Self-Blame and Self-Assertion in the Iliad. Transactions of the American Philological Association, v. 140, p. 1-32, 2010.

BOUVIER, David. Le sceptre et la lyre. L'Iliade ou les héros de la mémoire. Grenoble: Jérôme Millon, 2002.

BURKERT, W. Babylon, Memphis, Persepolis. Eastern contexts of Greek culture. Cambridge, London: Harvard University Press, 2004.

BURKERT, W. Das Lied von Ares und Aphrodite. Zum Verhältnis von Odyssee und Ilias. Rheinisches Museum für Philologie, v. 103, p. 130-144, 1960.

BURKERT, W. Mito e mitologia. Coleção ‘Perspectivas do homem'. Trad. Por M. H. R. Pereira. Lisboa: Edições 70, 1992.

CLARKE, W. M. Achilles and Patroclus in love. Hermes, v. 106, p. 381-396, 1978.

CLAY, J. S. The wrath of Athena. Gods and men in the Odyssey. Lanham; Boulder; New York; London: Rowman \& Littlefield, 1983; 1997.

COLLINS, L. Studies in characterization in the Iliad. Frankfurt am Main: Athenäum, 1988. (Beiträge zur klassischen Philologie, 189).

CUNLIFFE, R. J. A lexicon to the Homeric dialect. Norman: University of Oklahoma, 1963. $1^{\text {a }}$ ed. 1924.

DAVIES, Malcolm. The Judgement of Paris and Iliad Book XXIV. Journal of Hellenic Studies, v. 101, p. 56-62, 1981.

DAVIES, Malcolm. The judgements of Paris and Solomon. The Classical Quarterly, v. 53, p. 32-43, 2003.

DICKEY, E. Ancient Greek scholarship. Oxford, New York: Oxford University, 2007. 
DODDS, E. R. The Greeks and the irrational. Berkeley: University of California, 1951.

DOURADO-LOPES, A. O. A imagem dos deuses nos poemas homéricos. Arte e Filosofia, n. 15, p. 96-104, set. 2013, p. 96-104.

DOURADO-LOPES, A. O. Natureza dos deuses e divindade da natureza: reflexões sobre a recepção antiga e moderna do antropomorfismo divino grego. Kriterion. Revista de Filosofia do Departamento de Filosofia da UFMG, v. 122, p. 377-397, 2010.

DOVER, K. Greek popular morality in the time of Plato and Aristotle. Oxford: Oxford University; Basil Blackwell, 1974.

EBBOTT, M. The Wrath of Helen: Self-Blame and Nemesis in the Iliad. In: CARLISLE, M.; LEVANIOUK, Olga (Ed.). Nine Essays on Homer. Lanham: Rowman \& Littlefield, 1999, p. 3-20.

EBELING, H. (Ed.). Lexicon homericum. Leipzig: B. G. Teubner, 1885. 2 v.

EDWARDS, M. The Iliad: a commentary. Edited by G. S. Kirk. Cambridge: Cambridge University Press, 1991. v. 5.

ERBSE, H. Scholia graca in Homeri Iliadem (scholia vetera). Recensuit Hartmut Erbse. Berlin: Walter de Gruyter, 1969-1988. 7 v.

FARRON, S. The portrayal of women in the Iliad. Acta Classica, v. 22, p. 15-31, 1979.

FELSON, N.; SLATKIN, L. M. Gender in epics. In: FOWLER, Robert (Ed.). The Cambridge Companion to Homer. Cambridge: Cambridge University, 2004, p. 91-114.

FINKELBERG, M. (Ed.). The Homer encyclopedia. Chichester: Wiley-Blackwell, 2011. 3 v.

FRIEDLÄNDER, P. Lachende Götter. Die Antike, v. 10, p. 209-226, 1934.

GRAZIOSI, B. Inventing Homer. The early reception of epic. Cambridge, New York: Cambridge University, 2002.

GRAZIOSI, B.; HAUBOLD, J. Homer: Iliad, Book VI. Cambridge Classics. Cambridge: Cambridge University Press, 2010.

HAINSWORTH, B. The Iliad: a commentary. Edited by G. S. Kirk. Cambridge: Cambridge University Press, 1993. v. 3.

HALLIWELL, S. The uses of laughter in Greek culture. Classical Quarterly, New Series, v. 41, n. 2, p. 279-296, 1991.

HESIOD. Theogony. Edited with introduction and commentaries by M. West. Oxford: Clarendon Press, 1966.

HESIOD. The Works and Days. Edited with introduction and commentaries by M. West. Oxford: Clarendon Press, 1978. 
O EROTISMO DE HELENA NA ILÍADA: DIONISO, A PERSPECTIVA HOMÉRICA E O GOSTO DOS COMENTADORES

JANKO, R. The Iliad: a commentary. Edited by G. S. Kirk. Cambridge: Cambridge University Press, 1992. v. 4.

KIRK, G. S. The Iliad: a commentary. Edited by G. S. Kirk. Cambridge: Cambridge University Press, 1985. v. 1.

KIRK, G. S. The Iliad: a commentary. Edited by G. S. Kirk. Cambridge: Cambridge University Press, 1990. v. 2.

KULLMANN. Das Wirken der Götter. Untersuchungen zur Frage der Entstebung des homerischen 'Götterapparatts'. Berlin: Akademie Verlag, 1956.

LANG, M. L. Reverberation and Mythology in the Iliad. In: RUBINO, C. A; SHELMERDINE, C. W. Approaches to Homer. Austin: University of Texas Press, 1983. p. 140-164.

LEXIKON DES FRÜHGRIECHISCHEN EPOS. Göttingen: Vandenhoeck \& Ruprecht, 1979-2013.

LIDDELL, H. G.; SCOTT, R.; JONES, H. S. A Greek-English lexicon. Oxford: Oxford University Press, 1990.

LLOYD-JONES, H. The justice of Zeus. Berkeley: University of California Press, 1971.

LORAUX, N. Les expériences de Tirésias. Le féminin et l'homme grec. Paris: Gallimard, 1989.

MACLEOD, C. W. Homer. Iliad: book XXIV. Edited by C. W. Macleod. Cambridge; New York: Cambridge University Press, 1982.

MAYER, K. Helen and the $\triangle \mathrm{IO} \Sigma \mathrm{BOY} \Lambda$ H. American Journal of Philology, v. 117, p. 1-5, 1990.

MUELLNER, L. Helen's fatal attraction and its inversion. Classical Inquiries. Studies of the Ancient World from the CHS. [publicado online em 05/03/16] http://classical-inquiries.chs. harvard.edu/helens-fatal-attraction-and-its-inversion/

NAGY, G. Epic hero. In: FOLEY, J. M. (Org.). A companion to ancient epic. Malden, MA; Oxford: Blackwell, 2005, p. 71-90.

NAGY, G. The best of the Achaeans. Concepts of the hero in archaic Greek poetry. $2^{\text {nd }}$ ed. Baltimore: Johns Hopkins University Press, 1999 [1979]. Disponível em: http://nrs.harvard.edu/urn3:hul.ebook:CHS_NagyG.The_Best_of_the_Achaeans.1999.

OTTO, W. F. Dioniso. Imagem arquetípica da vida indestrutivel. Trad. por O. T. Serra. São Paulo: Odysseus, 2002.

PFEIFFER, R. History of classical scholarship: from the beginning to the end of the hellenistic age. Oxford: Oxford University Press, 1968.

REINHARDT, K. Das Parisurteil. In: Von Werken und Formen. Vorträge und Aufsätze. Godesberg: 1948, p. 11-36. 
RICHARDSON, N. The Iliad: a commentary. Edited by G. S. Kirk. Cambridge: Cambridge University Press, 1993. v. 6.

ROUSSEAU, P. La toile d'Hélène. In: BROZE, M. et al. Le mythe d'Hélène. Bruxelles: Editions Ousia, 2003, p. 9-43.

ROUSSEAU, P. L'égarement de Pâris. A propos d'Iliade, XXIV, 25-30. Uranie, v. 8, p. 33-49, 1998.

SCODEL, R. Listening to Homer. Ann Arbor: University of Michigan Press, 2002.

SLATKIN, L. The Power of Thetis: Allusion and Interpretation in the Iliad. Berkeley: University of California Press, 1995 [1991].

SOLMSEN, F; MERKELBACH, R.; WEST, M. L. Hesiodi Theogonia. Opera et dies. Scutum. Edidit Friedrich Solmsen. Fragmenta selecta. Ediderunt R. Merkelbach et M. L. West. Oxford: Clarendon Press, 1990 [1970].

SUTER, A. Paris and Dionysos: Iambos in the Iliad. Arethusa, v. 26, p. 1-18, 1993.

TRABULSI, J. A. D. Dionisismo, poder e sociedade na Grécia até o fim da época clássica. Belo Horizonte: UFMG, 2004.

VAN THIEL, H. Homeri Odyssea. Recognovit H. van Thiel. Hildesheim; Zürich; New York: Georg Olms, 1991.

VAN THIEL, H. Homeri Ilias. Recognovit H. van Thiel. Hildesheim; Zürich; New York: Georg Olms, 1996.

WEST, M. L. Greek epic fragments from the seventh to the fifth centuries. Edição, tradução, introdução e notas por M. L. West. Cambridge, MA; London: Harvard University Press, 2003.

WEST, M. L. Hellenica. Selected papers on Greek literature and thought. Oxford: Oxford University, 2011a. v. 1.

WEST, M. L. Hesiod: Theogony. Edited with introduction and commentaries by M. West. Oxford: Clarendon Press, 1966.

WEST, M. L. Hesiod: Works and days. Edited with prolegomena and commentary by M. L. West. Oxford: Clarendon Press, 1978.

WEST, M. L. The east face of Helicon. West asiatic elements in Greek poetry and myth. Oxford: Clarendon Press, 1997.

WEST, M. L. The Epic Cycle. A commentary on the lost Troy epics. Oxford: Oxford University, 2013.

WEST, M. L. The making of the Iliad. Disquisition \& analytical commentary. Oxford, New York: Oxford University, 2011b. 